\title{
Espacio urbano y movilidad: tendencias productivas y regulación en la ciudad de San Luis (Argentina)*
}

\author{
Urban space and mobility: productive trends and regulation in \\ the city of San Luis (Argentina)
}

\author{
Espaço urbano e mobilidade: tendências produtivas e \\ regulamentação na cidade de San Luis (Argentina)
}

Eliana Isabel Abraham**

\begin{abstract}
RESUMEN
Este artículo realiza un recorrido por las principales tendencias

industriales, digitales y turísticas aplicadas en la ciudad de San Luis (Argentina) durante las últimas décadas, a fin de comprender las relaciones entre ciudades intermedias, políticas productivas y transformaciones espaciales. Utilizaremos la mirada teórico-epistemológica que nos proponen los estudios en movilidad para reconocer la dinámica móvil que estructura a las ciudades actuales. Como resultado, el artículo propone una revisión respecto de la importancia que tiene la regulación del movimiento como un aspecto continuo de las políticas productivas aplicadas, así como en las transformaciones espaciales observadas. Estas intervenciones son configuradas en el marco de determinadas tendencias productivas que ponderan "el orden de lo visible" y
\end{abstract}

Palabras clave: espacio urbano, modelos productivos, movilidad, transformaciones espaciales.

\footnotetext{
* $\quad$ Este escrito integra una serie de indagaciones contenidas en la tesis doctoral en proceso denominada "Políticas de movilidad y experiencia: desplazamientos diferenciales en la ciudad de San Luis (Argentina)". Asimismo, parte de estas reflexiones se encuentran enmarcadas en espacios de investigación individuales y colectivos tales como "Tramas y conflictos urbanos en contextos de reestructuración del capital: indagación sobre procesos de patrimonialización y turistificación en tres ciudades medias argentinas (Córdoba, San Luis y Resistencia)" dirigido por la Dra. María Belén Espoz (UNCCONICET) y el programa de investigación permanente "Ideología, prácticas sociales y conflicto" (CIECS-CONICET) coordinado por la Dra. María Eugenia Boito.

** Argentina. Licenciada en Comunicación Social, Universidad Nacional de Córdoba, Argentina. Docente Auxiliar de la Facultad de Ciencias Humanas, Universidad Nacional de San Luis (Argentina). Becaria Doctoral del Consejo Nacional de Investigaciones Científicas y Técnicas (CONICET). San Luis, Argentina. elianaabraham9012@gmail.com
} 
la circulación ininterrumpida de bienes materiales y de cuerpos, aspectos distintivos del sistema de acumulación actual.

\begin{abstract}
This article reviews the main industrial, digital and tourist trends that have been seen in the city of San Luis (Argentina) over the last few decades, in order to understand the relationships between intermediary cities, productive policies and spatial transformations. We will use the theoretical-epistemological approach developed by mobility studies to recognize the mobile dynamics that structure today's cities. As a result, the article proposes a review of the importance of the regulation of movement as a continuous aspect of the productive policies applied, as well as in the spatial transformations observed. These transformations are conceived within the framework of certain productive tendencies that consider "the order of the visible" and the uninterrupted movement of material goods and bodies, distinctive aspects of the current system of accumulation.
\end{abstract}

\section{RESUMO}

Este artigo aborda as principais tendências industriais, digitais e turísticas aplicadas na cidade de San Luis (Argentina) durante as últimas décadas, a fim de compreender as relações entre cidades intermediárias, políticas produtivas e transformações espaciais. Utilizaremos o olhar teórico-epistemológico proposto pelos estudos de mobilidade para reconhecer a dinâmica móvel que estrutura as cidades atuais. Como resultado, o artigo propõe uma revisão a respeito da importância da regulamentação do movimento como um aspecto contínuo das políticas produtivas aplicadas, assim como nas transformações espaciais observadas. Estas intervenções são configuradas dentro da estrutura de certas tendências produtivas que refletem "a ordem do visível" e a circulação ininterrupta de bens materiais e de corpos, aspectos distintivos do sistema de acumulação atual.
Keywords: urban space, productive models, mobility, spatial transformations.

Palavras-chave: espaço urbano, modelos produtivos, mobilidade, transformações espaciais. 


\section{Introducción}

En las últimas décadas, las distintas modalidades de producción instauradas por los gobiernos de corte neoliberal aceleraron las transformaciones de los espacios urbanos latinoamericanos. Por una parte, la promoción de diversas concepciones de desarrollo inscriptas en las políticas de mercado recrudeció las desigualdades habitacionales, económicas y culturales entre las clases, así como también alteró, las formas de concebir y vivenciar la vida cotidiana en la ciudad, las tramas vinculares, la apropiación y acceso a bienes y servicios urbanos $\mathrm{y}$, fundamentalmente, las formas de moverse de los grupos sociales.

En este contexto, las grandes ciudades se han convertido en plataformas para la expansión del sistema de acumulación actual. Son diversas las investigaciones y estudios que rastrean las transformaciones suscitadas en las grandes urbes latinoamericanas (Boito y Espoz; 2014; Carman et al., 2013; Carrión, 2001; Janoschka, 2002). Sin embargo, las ciudades de escala menor han registrado -incluso con mayor visibilidad que las grandes metrópolis- las incidencias de los modelos de desarrollo aplicados en consonancia con los diseños urbanos paradigmáticos. En este sentido, las ciudades intermedias cobran un interés relevante para el campo de los estudios urbanos, en la medida en que evidencian ser potenciales espacios para la innovación, aplicación y experimentación de modelos urbanos diversos, así como formas de gobernanza locales para alcanzar niveles de productividad y competitividad determinados (Bellet y Llop, 2004). Estas ciudades no metropolitanas son impulsadas por políticas que inciden en la reconfiguración de sus estructuras embelleciéndolas, revalorizándolas, o turistificándolas, al igual que por la regulación de las relaciones de distancia-proximidad que influyen en las interacciones que traman los residentes en el espacio. La aceleración/ desaceleración de la circulación de bienes y cuerpos se convierte en un aspecto distintivo de los modelos y de las políticas que los integran. Así, sostenemos que frente a discursos asociados al paradigma tradicional que pregonan la sostenibilidad, la competitividad y la inteligencia de estas "ciudades-modelo", existen tramas profundas para las ciudades latinoamericanas, las que revelan escenarios de desigualdad que ponen en un lugar central al movimiento en tanto objeto de regulación. 
De esta manera, este trabajo establece relaciones entre las tendencias productivas y las transformaciones espaciales suscitadas en San Luis, como ciudad intermedia argentina. Dicho espacio urbano se constituye para nosotros en un lugar de lectura de estos procesos a partir de las distintas tendencias y modelos de desarrollo que imprimen ciertos "rasgos" al territorio ligados a lo industrial, lo técnicodigital, y/o lo turístico como marcas características de las intervenciones en los espacios. Estos escenarios muestran la importancia que tiene la regulación del movimiento y la circulación para estas políticas de desarrollo y para las funciones de intermediación que poseen las ciudades de escala menor. En este sentido, el enfoque analítico que proponen los estudios de movilidad (Sheller y Urry, 2018) nos permiten acercarnos a la comprensión del movimiento como objeto de estudio, así como a la complejidad que reviste la dinámica de lo urbano en contextos de intensificación de los efectos del modelo económico actual.

La estructura expositiva que proponemos está compuesta por un primer momento de argumentación teórica que repasa características generales de las ciudades intermedias, sus aspectos principales y la importancia que revisten estos espacios para la potenciación de la circulación de bienes y servicios a escala planetaria. En este sentido, observamos las conexiones existentes con la movilidad como locus de regulación de las principales políticas aplicadas en la observación de un caso concreto. Así, en un segundo momento describimos la implicancia de la aplicación de estos modelos productivos que tienden a ponderar, sobre todo en los últimos años, el "embellecimiento" y "revalorización" de distintos puntos de la ciudad. Describimos estas tendencias en clave histórica desde una posición que observa las distintas modificaciones territoriales como procesos en la vida de las ciudades pequeñas y medianas que, en el caso de San Luis, responden a las dinámicas de urbanización del sistema de acumulación actual.

\section{Ciudades (medias) y modelos productivos}

El avance de los procesos de industrialización a nivel global y la implicancia de los modelos urbanos sostenidos en el tiempo incentivaron el crecimiento exponencial de las ciudades, reorganizando los modos de vida y las relaciones existentes entre el centro y la periferia. Este cre- 
cimiento estuvo acompañado por la multiplicación paulatina de las brechas sociales, así como las distancias espaciales para el acceso a bienes y servicios urbanos que, como sabemos, se encuentran distribuidos desigualmente en los territorios. En este sentido, los procesos de contraurbanización intentan torcer los impactos del fenómeno de la urbanización sin límites, impulsando el crecimiento de pequeñas y medianas ciudades para la producción de sistemas urbanos sostenibles donde el decrecimiento sea la clave en la redistribución equitativa de los recursos ${ }^{1}$.

Las crecientes tendencias de urbanización y sobredensificación de los grandes conglomerados urbanos (por ejemplo Buenos Aires en Argentina o Sao Paulo en Brasil, entre otros) contribuyeron a la constitución de estos centros medianos que adquirieron predominancia por su cercanía regional a otras centralidades, rutas y conexiones para el flujo de personas, bienes y mercancías. En este marco, las ciudades de menor escala cobran una importancia relevante y se convierten en testigos sigilosos de la reconfiguración de los nuevos patrones de urbanización. El avance de las tecnologías de comunicación y el transporte permitieron que estos centros medianos pudieran potenciar las redes de conexión con otros puntos geográficos distantes, al tiempo de vigorizar sus economías locales, favoreciendo la apertura de fuentes de trabajo así como brindando oportunidades residenciales y educativas. Así, la característica de estos espacios radica en la dinámica de los intercambios mercantiles y relacionales que se desarrollan en los territorios, así como la capacidad que poseen como epicentros de conexiones y redes con otros puntos geográficos próximos.

Estas características suponen considerar las ciudades de una manera dinámica, introduciendo una concepción moderna en la definición de los actuales sistemas urbanos. En este sentido, existen distintas miradas en torno a las ciudades intermedias que trascienden

1 Según Arroyo (2001) la contraurbanización refiere a procesos de urbanización descentralizados nucleados en centros de menor tamaño que reciben desplazamientos poblacionales definitivos en sus espacios. En este sentido, la contraurbanización refiere a un cambio y ruptura con la tendencia de urbanización como fenómeno de concentración de las poblaciones en una ciudad. También es asociada a la revitalización de los espacios naturales. Sin embargo, el autor señala la ambigüedad que rodea al término que no establece distinciones claras con otro tipo de procesos como el de suburbanización. 
el criterio cuantitativo, destacando las múltiples funcionalidades de estos territorios ${ }^{2}$. La función de intermediación más que remitir a una postura cuantitativa refiere a un cambio de naturaleza - al decir de Capel (2009)—, que distingue a estas ciudades como potenciales centros de conexión y atracción, además de plataformas para la aplicación de políticas públicas innovadoras. Esta capacidad para tejer redes y distancias cortas las convierten en espacios principales para la construcción de "identidades regionales" y como innovadores "centros industriales, comerciales, mineros, de transportes o de servicios, pero otras poseen funciones múltiples en relación con su papel en el espacio circundante" (Capel, 2009, p. 13). Al respecto, existen distintas investigaciones realizadas acerca de las ciudades intermedias que las postulan como nuevos paradigmas urbanos o respuestas esperanzadoras para la construcción de sistemas urbanos equilibrados, plataformas de políticas redistributivas, formas de gobernanza y/o participación local. Sin embargo, frente a las múltiples experiencias prevalecientes en el escenario europeo, las ciudades del sur global presentan particularidades propias que se encuentran ligadas a los impactos de los modelos de desarrollo urbano instalados en América Latina durante los gobiernos democráticos de corte neoliberal.

En ese marco, la profundización de las políticas de desregulación y liberalización iniciadas a fines de los 70 y profundizadas en los 90 con la aplicación de las medidas del Consenso de Washington aparecen como las principales causas del desarrollo de patrones de diferenciación espacial en las ciudades latinoamericanas. La propagación de conjuntos habitacionales precarios (callampas, favelas y/o villas miseria) se convierten en espacios contrastantes con la emergencia de polos

2 La primera postura toma en consideración el tamaño geográfico y talla de las poblaciones que las componen. Para algunos autores, las ciudades intermedias poseen entre "20.000 y 150.000 habitantes" (Sassone, 1998), mientras que para Bellet y Torné (2004), pertenecientes al "Programa Ciudades Intermedias y urbanización mundial" (UIA-CIMES), la talla poblacional ronda entre 50.000 y 1.000 .000 de habitantes. El programa UIA-CIMES es un espacio creado en el año 1996 para la reflexión de la ciudades, el papel de la arquitectura y el urbanismo, y el trabajo institucional /profesional sobre las ciudades intermedias. La iniciativa intenta construir un marco de cooperación y establecimiento de redes entre distintos investigadores para repensar las problemáticas de las ciudades desde una perspectiva metodológica. Desde el año de su fundación, el UIA-CIMES ha elaborado una serie de documentos que sintetizan el estado actual de las ciudades a partir de la sistematización de distintos colaboradores alrededor del mundo. 
de riqueza pujantes, revitalizados por el peso creciente de los capitales inmobiliarios y la expansión de los flujos financieros en el desarrollo urbano. En tanto, la intervención de organismos internacionales (Banco Mundial, Banco Interamericano de Desarrollo y Fondo Monetario Internacional) propició las transformaciones espaciales suscitadas en las ciudades como correlato de las medidas económicas instauradas por los gobiernos cuyos roles también fueron reconfigurados en el escenario geopolítico.

La serie de transformaciones espaciales suscitadas a partir de estos procesos económicos incentivó el desarrollo de grandes emprendimientos urbanos para generar atracción y plusvalía en las urbes. En este sentido, algunas de las características que moldearon los rasgos que asumieron las ciudades latinoamericanas están relacionadas con la creciente mercantilización del espacio urbano a partir del montaje de importantes centros de entretenimiento y ocio, tales como los malls y centros comerciales, además de la producción de conglomerados residenciales exclusivos para incentivar la "imagen" (city marketing) de los espacios en la vitrina global del mundo. Estas operaciones de embellecimiento de los espacios tendieron a la revalorización del patrimonio urbano y a las distintas expresiones de lo cultural, reutilizadas para la industria del turismo en la producción de mercancías de experiencias articuladas en la dinámica global-local propuesta por los capitales móviles. Así, la reconfiguración de los patrones económicos, políticos y culturales, motorizada por la globalización, produjo la aceleración de los procesos de industrialización en distintas ciudades menores que incorporaron infraestructura para revalorizar sus territorios e incentivar las economías locales. En este sentido, la descentralización política y administrativa para regular las intervenciones de los gobiernos permitieron la generación de nuevas centralidades territoriales que incrementaron su porte e incidencia en el escenario urbano.

Podemos decir que la emergencia de las ciudades intermedias puede ser ubicada en estos procesos de rearticulación de las relaciones territoriales donde la competitividad interurbana se convierte en un aspecto considerable para el desarrollo. Para dicho crecimiento, la técnica recobra un especial interés a partir de la incorporación de infraestructura moderna y el tendido de comunicaciones que permitieron la aproximación de territorios distantes y/o el establecimiento de 
nuevas articulaciones rurales-urbanas en este mapa descentralizado. En ese marco, la creciente regulación de los tránsitos y desplazamientos se suma a los esfuerzos de conectividad y digitalización, a partir de sofisticados programas de vigilancia y control que caracterizaron a las tecnologías de información puestas para la modernización de las ciudades.

El paradigma de innovación digital se instala como una condición clave en la reconfiguración territorial, dado que habilita la aceleración en el intercambio de las comunicaciones y de la información. Para Carrión (2014), la "revolución tecnológica" produjo una alteración de las distancias al incrementar o reducir las accesibilidades a los bienes y servicios, convirtiendo los espacios en "continuos y discontinuos, que dejan entre sí intersticios separados, y otros integrados y homogeneizados" (p. 203). En este sentido, la incorporación de infraestructuras para actividades industriales permitió la promoción de mayores movimientos migratorios a estos pequeños centros urbanos, además de la complejización de las redes de información y el control de los servicios y bienes en la ciudad. Esta innovación digital se expande en distintos aspectos en la vida de las ciudades, los que contemplan desde la infraestructura física y de servicios, la iluminación, seguridad, regulación de material contaminante, gestión de desechos, hasta sensores de vigilancia e información, además de una reconfiguración de las actividades sanitarias y/o educativas. Schiavo y Gelfuso (2018) destacan al mismo tiempo la capacidad de estas ciudades en la generación de información para "definir pautas de comportamiento o resultados probables y traducirlos en conocimiento real, permitiendo actuar de manera informada" (p. 434). Así, la dirección y control del desplazamiento se constituye como uno de los rasgos que aparece como distintivo en este tipo de ciudades donde el tendido de redes entre puntos estratégicos y la producción de circuitos turísticos atractivos, así como el despliegue de sistemas de comunicación, entre otros aspectos, son indispensables para la condición circulatoria de lo urbano.

A las características generales que componen la función de intermediación de estos espacios, sumamos el atravesamiento de movilidades practicadas y reguladas, que tensionan la aparente interconexión territorial, así como la accesibilidad a bienes y servicios urbanos. En 
este escenario, la movilidad ${ }^{3}$ como objeto y/o enfoque nos permite observar un mapa de relaciones de distancia-proximidad entre cuerpos, bienes y mercancías que son marcadamente conflictuales y desiguales. En ella convergen procesos que involucran prácticas, tecnologías y sentidos que refuerzan la condición circulatoria de las ciudades. Esto implica que los desplazamientos en la ciudad son modulados y/o regulados por los patrones urbanos aplicados en los espacios y en los modelos de desarrollo implementados para la motorización de los flujos de capitales. En este sentido, las distintas tendencias productivas ejecutadas en las ciudades resguardan, controlando y monitorizando, las circulaciones y movilidades a partir de "un entramado de racionalidades y tecnologías en el que se condensa el modo en que ha de ser concebido y construido el espacio" (Mendiola, 2013, p. 436). De esta manera, la indagación de la dinámica de las ciudades asociada al flujo de los capitales y a las distintas políticas productivas implementadas resulta de un interés central para la comprensión del desarrollo fragmentado de los espacios.

Para el caso de las ciudades pequeñas y medianas, la recomposición de sus territorios - basada en distintas políticas productivas- ha resultado de importancia para comprender la potenciación de sus espacios en centros de atractivo industrial, turístico y/o digital donde se caracteriza "la dirección e intensidad de los flujos de personas y transportes, los flujos de bienes, los flujos telefónicos, los flujos postales" (Sassone, 1998, p. 17). Las dinámicas móviles del capital instauran nuevas modalidades de producción del espacio a partir de la interconexión y la aceleración/desaceleración de los movimientos que se expresan en nuestras ciudades en distintos escenarios y bajo diferentes modalidades. Así, estas ciudades además de ser territorios de experimentación de desarrollo también se constituyen en otros correlatos de desigualdades espaciales expresas y/o manifiestas en las formas móviles que asumen las ciudades en el tiempo.

Para revisar algunos de estos supuestos, remitimos a determinados escenarios de la ciudad de San Luis (Argentina), rastreando los distin-

3 A partir de la década del 90, el denominado "giro de la movilidad" y/o "paradigma móvil" propuesto por Sheller y Urry (2018) inicia una serie de indagaciones en torno a la movilidad vinculada con múltiples aspectos en la vida de los espacios urbanos y en diálogo con distintos campos disciplinares. 
tos modelos de desarrollo que intervinieron y reconfiguraron espacialmente el territorio. Algunas de las indagaciones que destacamos refieren al desarrollo histórico de la ciudad (Segovia, 2012), otras se centran en las implicancias del sector turístico en la provincia (Trivi, 2014) y, por último, la configuración urbana desde la clave políticas socialesexperiencias de los residentes de la ciudad (Seveso, 2015), que permitieron construir una mirada comprensiva en torno a la cuestión urbana en la provincia de San Luis. Del mismo modo, la pesquisa de Szupiany (2016), que si bien analiza la ciudad de Santa Fe, nos ofrece una perspectiva histórica para observar la incidencia de las infraestructuras de movilidad en la morfología de los espacios urbanos y en la distribución y fragmentación que asumen las ciudades contemporáneas.

Así, las tendencias productivas que exponemos responden a las transformaciones espaciales evidenciadas en las últimas tres décadas, caracterizadas por rasgos prevalecientes asociados con lo industrial, digital y turístico que acompañaron las funciones de intermediación y centralidad que adquirió la ciudad en el tiempo. La circulación y el movimiento se constituyen como nexos clave de cada una de las transformaciones que evidenciamos. Tal como observaremos en el caso de la ciudad de San Luis, estos aspectos han sido un elemento de regulación constante por parte de los gobiernos y centro de disputa en la definición y en las maneras de vivenciar los espacios urbanos.

\section{Estrategia metodológica}

Entendemos que para comprender los espacios urbanos necesitamos revisar las condiciones materiales que posibilitaron su configuración presente. Esto es, revisar las tramas de intereses, políticas, tendencias, y/o definiciones que dominaron las formas de estructuración de la ciudad en el transcurso del tiempo. Para ello, la revisión de "qué se ha dicho" y/o construido respecto de la ciudad resulta de vital importancia para establecer puntos de partida, así como entradas posibles para este recorrido.

De esta manera, este artículo pretende constituirse en una primera aproximación al estudio de la ciudad de San Luis, a partir de un abordaje cualitativo e interpretativo desde/en el enfoque de la movilidad. Por un lado, la sistematización bibliográfica arrojó una cantidad relativa de documentos en torno al desarrollo urbano de la ciudad procedentes 
de distintas áreas temáticas, lo que permitió identificar elementos para la comprensión de las formas que fue asumiendo el espacio urbano y/o sus relaciones con las distintas tendencias productivas promovidas en los territorios. Por otro, la revisión y recolección de archivos oficiales emitidos por el gobierno provincial en sus plataformas de difusión permitieron identificar los posicionamientos oficiales, así como las formas de concebir la ciudad dentro de la esfera estatal. Otro lugar de observación importante fue la búsqueda de noticias y artículos de los principales medios de comunicación locales que complementaron la información relevada. En este sentido, la indagación documental permite imputar un sentido histórico a los procesos sociales y constituir un marco de referencia para su comprensión.

Los propósitos de la investigación social para el análisis cualitativo involucran decididamente la indagación documental. En este sentido, Valles (1999) refiere "la combinación de observación y entrevista que se da en la lectura de materiales documentales" (p. 120), además de destacar la posibilidad de observar e interrogar los textos con la misma intensidad que se analiza cualquier práctica social. En nuestro caso, nos permite construir lecturas interpretativas a partir de documentos materiales para aproximarnos a la configuración de la ciudad, así como en las características de los escenarios urbanos y en los marcos de conflictividad y desigualdad que los atraviesan.

Un abordaje metodológico que involucre el análisis documental nos provee no solo de una dimensión histórica en torno al fenómeno urbano, su desarrollo y transformaciones espaciales a partir de investigaciones y documentos de archivos oficiales, sino también posibilita indagar, como horizonte futuro, las tramas subjetivas que rodean esos testimonios, perspectivas y visiones del espacio. Así, pretendemos periodizar los momentos de configuración de la ciudad de San Luis a partir de tres figuras (ciudad industrial, ciudad digital y turística) que sintetizan transformaciones, procesos y prácticas, a la par que nos permiten acercarnos a la indagación de las movilidades que se producen en ella. A modo de organizarnos temporalmente, observamos estas tendencias productivas que se reconfiguran en el tiempo y se muestran espacialmente, evidenciando los impactos de los procesos de acumulación actual. La experiencia como investigadores y, fundamentalmente, de habitantes urbanos se constituye en una primera herramienta de 
inmersión al estudio de la ciudad en este recorrido que esbozamos y en la comprensión de algunos escenarios que exponemos.

\section{La ciudad de San Luis: orden urbano y tendencias productivas}

La ciudad de San Luis tuvo un papel subsidiario en la historia del proceso de urbanización argentino, al igual que otras ciudades consideradas "de paso" hacia centros urbanos mayores. Fundada en 1594 por el teniente Luis Jofré de Loaysa Meneses, el territorio formaba parte del "Corregimiento de Cuyo", dependiente del Virreinato del Perú y con punto central en la ciudad de Mendoza. Hacia el año 1689 la ciudad se traslada tres veces hasta su emplazamiento final en el centro-norte (actualmente Departamento Juan Martín de Pueyrredón) de la provincia ${ }^{4}$. Dicha ubicación geográfica la posiciona cerca de la zona de serranías, donde actualmente se sitúan las localidades de Potrero de los Funes, Juana Koslay y La Punta. Este emplazamiento ha influenciado en la centralidad que adquiere la ciudad de San Luis como capital provincial $^{5}$ siglos más tarde respecto de dichos territorios circundantes.

Historiar el proceso de configuración de la ciudad de San Luis nos demandaría un análisis más complejo y extenso que trascendería los límites de este escrito. Sin embargo, es posible rastrear el pasaje de un estado subsidiario de la ciudad - caracterizado por economías agrarias deficientes- hacia una función protagónica dentro de la región, que la ubica a fines de los 70 como ciudad industrial de escala media. A partir de esa época, la implementación del "Régimen de Promoción Industrial” ${ }^{6}$ permitió la expansión de la ciudad "por fuera" de sus bor-

4 El posicionamiento de la provincia de San Luis la ubica en un lugar estratégico dentro del interior de la geografía nacional. El territorio provincial se encuentra en el centro de Argentina con límites en Mendoza y San Juan al oeste, La Rioja y Córdoba al norte y con La Pampa al sur. Además, se constituye en el principal corredor ferroviario bioceánico que comunica Santiago de Chile y Buenos Aires.

5 Según datos del último censo nacional (INDEC, 2010), la ciudad de San Luis cuenta con una densidad poblacional de unos 204.019 habitantes. Parte significativa del creciente aumento de pobladores se relaciona a las políticas industriales implementadas a partir de la década del 80 y que suplantaron a perfiles productivos dirigidos al sector primario (agricultura y ganadería) durante el modelo agroexportador.

6 En 1973 el gobierno de San Luis acuerda con el "Acta de Reparación Histórica” junto a las provincias de La Rioja y Catamarca y posteriormente, Santa Cruz. Este acuerdo permitió la promoción de las actividades industriales en estas provincias en consonancia con un impulso de las economías regionales a nivel nacional. La "reparación" de la 
des, por medio de la radicación de parques industriales que impulsaron la economía regional, la promoción de inversiones de capitales privados y el desplazamiento progresivo de población migrante desde el interior rural-provincial hacia los centros urbanos mayores de la provincia, como es el caso de San Luis y Villa Mercedes. Este proceso de industrialización coincide con el fenómeno de reestructuración espacial indicado por Sassone (1998) para explicar la descentralización en el sistema urbano argentino, caracterizado por el papel revitalizador e innovador de ciudades de menor escala.

Figura 1.

\section{Conglomerado Gran San Luis-El Chorrillo}

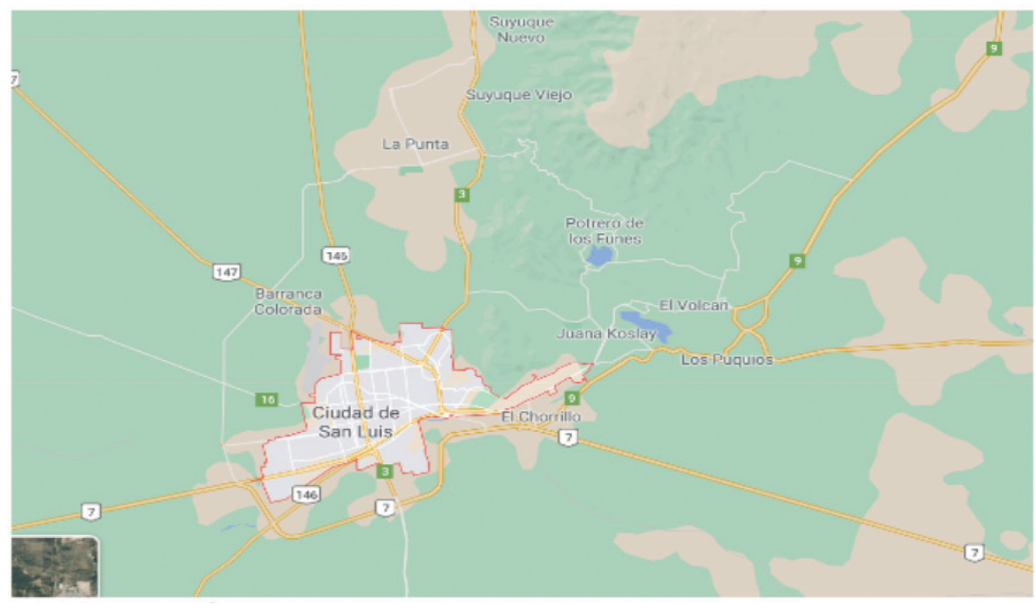

Fuente: Google Maps.

Para el caso de San Luis, el "salto cuantitativo" en términos poblacionales registró las bases para la redefinición del papel de la ciudad en los periodos posteriores. En este sentido, la ciudad capital se instala dentro de los parámetros de la talla poblacional que las definiciones cuantitativas realizan en torno a las ciudades intermedias ${ }^{7}$

Nación hacia estos territorios estuvo fundamentada por el apoyo que brindaron durante el periodo de independencia así como en "la organización del país sobre las bases federales" (Ley 5.500).

7 Si bien las políticas industriales reforzaron la centralidad de estas ciudades, también produjeron un "desequilibrio regional" a partir del vacío demográfico, lo que ocasionó nuevos paisajes de polarización social en unidades territoriales rurales. "Si se to- 
(204.019 habitantes según elINDEC (2010)) Asimismo, la serie de transformaciones que se originaron a partir del modelo de desarrollo industrial dieron inicio a un paquete de políticas que otorgaron una mayor centralidad y dinámica a la urbe y a los territorios próximos a su emplazamiento. Estas estuvieron caracterizadas por intervenciones que incidieron no solo en la reconfiguración de los espacios urbanos (embelleciéndolos, revalorizándolos, y/o turistificándolos), sino también en la regulación de las relaciones de distancia-proximidad y/o las movilidades practicadas y reguladas que traman los pobladores en el espacio.

Algunos de los escenarios que exponemos en este artículo integran una serie de procesos acontecidos en las ciudades argentinas en el marco de profundas dinámicas de transformación espacial que impulsaron un desarrollo urbano fragmentado, cuyas características adquieren fuerza a partir de políticas de apertura al mercado y una fuerte regulación estatal. A decir de Janoshcka (2002), en la Argentina "las reformas económicas de los años 90 que apuntaban a contraer el Estado mediante privatizaciones de empresas públicas y el desmantelamiento del sistema social limitaron seriamente la capacidad de gestión estatal" (p. 2). En materia urbana, esto produjo la intervención creciente de organismos internacionales en el diseño de las ciudades, así como en las formas de desarrollo que asumirían la gestión de los espacios. Posteriormente a la revuelta social a partir de la debacle económicapolítica del 2001en Argentina, estas políticas promovidas por las dinámicas globales del capital móvil impactan en los espacios urbanos en diferentes aspectos, no solo en la espacialización de la pobreza o en el fenómeno de las urbanizaciones privadas, sino también en la reconfiguración de nuevas centralidades urbanas y en las maneras de concebirlas. Así, entendemos que los modelos productivos impulsados por el Estado poseen, como corolario, expresiones espaciales que caracterizan las ciudades en su materialidad, en las maneras de enunciarla ${ }^{8}$,

man en cuenta las variaciones ocurridas a partir de 1980, se observa que mientras que los departamentos más alejados de los parques industriales llegaron a perder más del $20 \%$ de población, el departamento capital duplicó la cantidad de habitantes y el departamento Pedernera aumentó su población en 70\%" (Busetti, 2007, p. 41).

8 Por ejemplo, podemos mencionar el caso de la ciudad de Valparaíso (Chile) conocida como una "ciudad portuaria" debido al desarrollo e intercambio mercantil y turístico existente en los bordes de sus costas. La ciudad de Mendoza es conocida como la "capital 
así como en las formas de significarlas, percibirlas y sentirlas por sus habitantes.

Dichas transformaciones se encuentran sustentadas en distintos modelos de desarrollo que fueron definiendo la conformación de los rasgos de la ciudad (industrial, digital y turístico), los que motorizan la condición circulatoria, flujos de capitales, cuerpos y mercancías. En este sentido, el siguiente recorrido permite "escenificar" algunos momentos en la vida de una ciudad latinoamericana que no deben entenderse como compartimentos temporales estancos, sino como rasgos característicos del espacio que se superponen presentando dominancias - en algunos periodos más que en otros- $-\mathrm{y} / \mathrm{o}$ se encuentran rezagados frente a la impronta de nuevos horizontes de desarrollo.

\section{La ciudad industrial ${ }^{9}$}

Según indicamos antes, a mediados de los 70, la aplicación del Régimen de Promoción Industrial produjo transformaciones en la estructura urbana de la ciudad. Las tendencias poblacionales "expulsógenas" de la provincia de San Luis cambian a partir de la radicación progresiva de industrias que incentivaron la economía regional y la promoción de inversiones a partir de un beneficioso sistema impositivo. De esta manera, San Luis y Villa Mercedes representaron las ciudades más favorecidas por la implementación de las políticas industriales que habilitaron periodos de alto rendimiento económico, desarrollo de la industria local y una notoria reestructuración del componente poblacional que tiende a "profesionalizarse" para radicarse en los centros urbanos. La política industrial reforzó la centralidad de estas ciudades pero al mismo tiempo produjeron un desequilibrio regional a partir del vacío demográfico que provocaron en los territorios rurales, en tanto nuevos escenarios de polarización social (Busetti, 2007) ${ }^{10}$. En

mundial del vino" por su producción vitivinícola con alcance nacional e internacional desde el año 1987. En este sentido, la incidencia de los impulsos productivos de los territorios se encuentra relacionados con las formas de percibir y recrear dichas ciudades. 9 Tomaremos las figuras utilizadas con fines analíticos construidas por Seveso (2015) en torno a la "ciudad industrial" y "ciudad digital" para ilustrar las modificaciones en los "rasgos" que ha asumido la ciudad de San Luis en el tiempo. En este apartado agregamos una tendencias más que se inscribe en la última década en consonancia con los modelos productivos proyectados por la tecnocracia en el espacio urbano.

10 "Si se toman en cuenta las variaciones ocurridas a partir de 1980, se observa que, mientras que los departamentos más alejados de los parques industriales llegaron a per- 
este sentido, la situación de disparidad se produce "por fuera" del proceso de industrialización de estos centros urbanos, donde los territorios agrestes circundantes quedan relegados de políticas que incentivaran sus economías locales, predominantemente dedicadas al sector agro-ganadero. Esto constituyó "espacios ganadores y perdedores de dinámica, de empleo, de calidad de vida (...) las políticas públicas provinciales, lejos de orientarse a atenuar estas desigualdades, tendieron más bien a profundizarlas" (Busetti, 2007, p. 45) ${ }^{11}$. Como contraparte de este fenómeno, las ciudades principales reorganizaron sus territorios expandiendo la mancha urbana para la radicación de parques industriales y de una nueva masa poblacional a partir de activas políticas de vivienda ${ }^{12}$. Tuvo como papel importante para este proceso el trazado de la Ruta Nacional $\mathrm{N}^{\circ} 7$, que permitió la localización de gran parte del sector industrial y de la población migrante, además de la provisión de servicios de agua, luz y tendido eléctrico. Paralelamente, el uso del suelo se modificó recambiando tierra agreste propicia para actividades agroganaderas por la utilización de superficie urbana-industrial, aprovechable para el montaje de parques industriales en distintos puntos del territorio. Paulatinamente la ciudad vivencia un proceso de expansión, convirtiéndose en el centro de actividades industriales y en uno de los epicentros urbanos más importantes de la provincia.

Resulta importante mencionar que el movimiento industrial ha tenido variaciones en el tiempo, mostrando diferenciaciones en sus efectos en términos de "transformaciones económicas" (Busetti, 2007). Así, se registra "un alto promedio anual de crecimiento económico posterior a las leyes de promoción industrial hasta 1998 (...) eviden-

der más del $20 \%$ de población, el departamento capital duplicó la cantidad de habitantes y el departamento Pedernera aumentó su población en 70\%" (Busetti, 2007, p. 41).

11 Pese al crecimiento industrial evidenciado en la capital y Villa Mercedes frente a otros municipios de la provincia, se registra en Villa de Merlo - ubicada en el Departamento Junín - un incremento poblacional a partir del incipiente impulso turístico en la zona del noroeste provincial.

12 Busetti (2007) afirma que la implementación de políticas industriales produce tres tipos de transformaciones. Una primera modificación de tipo económico que impacta en la estructura del trabajo, el sistema financiero, el consumo, y, fundamentalmente, el cambio de un modelo productivo a otro. A nivel social, estas transformaciones se traducen en movimientos demográficos y/o la concentración de mano de obra obrera/fabril además de un incipiente "proletariado industrial". Por último, una transformación espacial que se traduce en la "concentración ligada a la localización de las industrias y a los servicios derivados (...) las ciudades se erigen en centros de atracción, con el papel de agentes organizadores del espacio" (p. 36). 
ciando después un crecimiento económico más moderado hasta fines de los años 90" (Becerra et al., 2014, p. 4). A medida que la ciudad se densifica incorporando nuevas infraestructuras y población trabajadora migrante del interior provincial y del resto del país, en el interior de los centros urbanos persisten los escenarios de marginalidad como enclaves funcionales al modelo de acumulación neoliberal implementado a nivel nacional. En este sentido, los altos índices de productividad y crecimiento económico evidenciados durante los primeros años de aplicación del Régimen de Promoción Industrial empiezan a decrecer. La actividad manufacturera muestra limitaciones a fines de la década del 90 y comienzos de los $2000^{13}$, con excepción de su pico máximo registrado en 1997. El Informe Productivo Provincial (2018) a partir de datos de la Organización para la Cooperación y el Desarrollo Económicos (OCDE) asegura que a principios de los 2000 el número de empresas industriales decreció hasta un 31,5\% (494 industrias) frente al punto máximo de 721 emplazamientos industriales registrados en 1999. Este contexto incidió en el tejido social de manera tal que, hacia fines de la década del 90 y principio de 2000, los valores de pobreza registraron un 35,9\%, mientras que un 11,6\% de la población estuvo sumida en situación de indigencia. Estos indicadores aumentaron hacia el año 2002 (53\% para la pobreza y un $24,8 \%$ en indigencia), situando a la provincia "más cerca de las regiones castigadas como el conurbano bonaerense que de otras provincias con menores valores de pobreza" (Olguín y Busetti, 2003, p.13).

Algunos de los puntos explicativos del debacle de las industrias en la provincia - fundamentalmente aquellas radicadas en San Luis - estuvieron relacionados con la imposibilidad de desarrollar manufactura propia. La ausencia de una integridad productiva originó "el desarrollo de establecimientos precarios y de eslabones de matrices radicadas en otros lugares del país, que situaban localmente su cadena final de producción ... con el solo objetivo de recibir los beneficios impositivos"

13 El escenario a nivel nacional se encuentra teñido de protestas entre mediados de los 90 y comienzos de 2000. Numerosos estudios sociales refieren a este momento en el país como "quiebre" de lazos sociales y de las redes de contención existentes referidos a los procesos de estructuración social (Scribano, 2008). La lógica de la fragmentación intenta ser contenida a partir de la emergencia de organizaciones sociales que a partir de repertorios de acción colectiva escenifican las fallas e incompatibilidades sistémicas del nuevo patrón de acumulación. 
(Seveso, 2015, p. 143). En este sentido, es posible afirmar que el crecimiento económico producido por la "promoción industrial" estuvo atravesado por el involucramiento de un empresariado local industrial deficitario, dependiente de los incentivos estatales y con una escasa integración en la economía provincial. Así, los beneficios impositivos de las políticas industriales fueron aprovechados por capitales privados que obturaron el desarrollo de las industrias locales y generaron mano de obra precarizada en aumento a partir de una órbita especuladora que se intensificó con la crisis del 2001.

Como en la mayoría de las provincias argentinas en preludios de la crisis del 2001, las brechas entre ricos y pobres aumentaron, así como los puestos de trabajo de baja calificación que permitieron afianzar una línea de montaje de trabajo precaria y expulsiva. Las consecuencias de la lógica de acumulación involucraron la disminución de puestos de trabajo, lo que originó un crecimiento de la desocupación, la subocupación, el empleo público y la proliferación de trabajos informales (Olguín y Busetti, 2003). En este marco, cobró relevancia la implementación de programas de transferencia condicionada como respuesta al aumento de escenarios expulsivos y de pobreza en toda la extensión de la cartografía social. Estas distintas modalidades de políticas sociales fueron ejecutadas a nivel nacional para paliar las condiciones de pobreza estructural ocasionadas por las medidas de corte neoliberal y la polarización creciente. Las mismas evidenciaron formas novedosas de inserción de los pobres al mercado laboral a partir de la formación de oficios, la transferencia directa de ingresos así como fuentes alternativas a bienes de consumo o generación de empleo. El trabajo aparece en cada una de las experiencias como centro de regulación de las políticas sociales implementadas en la Argentina y en distintos países latinoamericanos en tiempos de crisis procíclicas. En nuestro país podemos mencionar la ejecución del Plan Jefes y Jefas de Hogar (2002), consistente en prestaciones asistenciales a numerosas poblaciones de personas desocupadas con hijos a cargo. El programa no solo implicó una "herramienta para la política social, sino principalmente como instrumento para apaciguar un conflicto social de características inéditas que ponía en juego la continuidad del sistema político institucional" (CELS, 2003).

En el caso de San Luis, la ejecución del Plan de Inclusión Social desde el año 2003 hasta la actualidad permitió la contención de los 
agentes expulsados durante la etapa industrial, a partir de la asistencia estatal en tanto lugar donde reinventarse como "sujetos productivos" desplazados por el "ensueño" industrial. La implementación del plan también muestra el papel de las políticas sociales como dispositivos regulatorios del ordenamiento territorial (e ideológico), en tanto que también disponen los cuerpos y sus energías sociales en el espacio urbano. En este sentido, creemos que funcionan como modalidades de intervención que inciden en la conformación de una segregación por default en la medida que es "producida indirectamente por una conjunción de políticas de olvido por parte del Estado" (Carman et al., 2013, p. 21). Resulta importante destacar el apelativo de "inclusión", el que a partir de este periodo ha operado discursivamente como elemento característico de las nuevas intervenciones estatales. Así, estas medidas sociales persiguieron "incluir" a los desplazados del sistema a partir de la movilización de "las 'potencialidades de los pobres', para facilitar su acceso a recursos monetarios, mediante la inserción en programas de capacitación, emprendimientos productivos, autoempleo y/o el desarrollo de redes comunitarias" (Seveso, 2018, p. 2). Estas medidas sociales tienden a reducir —en el plano discursivo- las diferenciaciones sociales a partir del fomento de una "cultura del trabajo", pero actúan como doblez, generando condiciones de precarización laboral que favorecen el mercado de trabajo informal.

La emergencia de los "expulsados" del periodo industrial —en tanto nuevos pobres estructurales - produjo la aplicación de estas políticas de corte social que introducirían otras fronteras materiales y simbólicas, sumadas a las barreras espaciales existentes. En este sentido, la implementación del modelo neoliberal favoreció la acumulación y concentración de la riqueza cuya expresión espacial estuvo manifestada en la producción de escenarios de habitabilidad diferenciales. Las condiciones de desigualdad social comprobables en los indicadores y variables, así como en las decisiones/intervenciones de los gobiernos para contrarrestar la pobreza establecen sus articulaciones estratégicas con la lógica fragmentaria de lo "urbano". Así, por ejemplo, la producción y expansión de exclusivos circuitos residenciales hacia la zona de serranías (Juana Koslay y Potrero de Funes), a pocos kilómetros de San Luis, coincide con el auge del "retorno a lo natural" de las clases acomodadas en los grandes conglomerados urbanos a nivel nacional. La generación de escenarios contrastantes a partir del desarrollo 
incipiente de urbanizaciones cerradas no se encuentra por fuera del modelo de expansión urbana privatizada tan característico del área metropolitana de Buenos Aires, como han evidenciado los trabajos de Svampa (2005) sobre los countries y/o barrios cerrados. Al mismo tiempo, se fortalece la circulación y los vínculos con estas ciudadessatélites que quedan conectadas con los centros urbanos próximos a partir del tendido de calles, nuevas pavimentaciones y alumbrado público, como aspectos de una "transformación por proximidad/conectividad" basada en una modificación del paisaje rural donde las sierras y "lo verde" se constituyen en características distintivas. Desarrollaremos este aspecto más adelante; sin embargo, resulta importante mencionar que las articulaciones espaciales serán más aceleradas en periodos posteriores a partir del tendido de un moderno sistema de autopistas que conectará gran parte del territorio provincial. Así, lo "urbano" servirá de conexión entre la ciudad y lo natural a partir de una "complementariedad fáctica" - encubierta por una demarcación y diferenciación "ideal" históricamente constituida entre la ciudad y el campo- caracterizada por dependencias funcionales y mercantiles (Seveso, 2018). La circulación entendida como proceso y medio a decir de Seveso se constituye como premisa clave de las intervenciones urbanas y de las distintas modalidades de regulación de los vínculos que estas producen en el espacio y en los horizontes de desarrollo impulsados por el gobierno. En este sentido, la impronta industrial continúa - sin alcanzar sus históricos índices de productividad de los 90-, pero reduce sus alcances para avizorar un modelo de desarrollo ligado al aumento de las circulaciones mercantiles e informacionales que convergen simultáneamente con las formaciones socioproductivas del periodo anterior.

\section{La "ciudad digital": en la geolocalización está la clave}

Si el Régimen de Promoción Industrial implementado en la provincia durante el periodo 1980-1990 permitió la reestructuración del territorio en múltiples aspectos - expansión de las economías regionales, fuertes inversiones en infraestructuras urbanas, aumento de la movilidad espacial de las zonas rurales hacia la ciudad de San Luis y la expansión de la mancha urbana hacia la periferia a partir del emplazamiento de las industrias-, paulatinamente, los cambios en el territorio devenidos en las próximas décadas imprimieron un "sello" distinto 
de las intervenciones y modificaciones territoriales. Frente a la crisis del 2001 que azotó al país en toda su extensión geográfica, las políticas industriales aplicadas en San Luis impidieron una transformación en la sociedad y en el mercado del trabajo en la provincia que continuó siendo desfavorable y de oportunidades laborales escasas. Pese a estas características, el Estado operó sobre esta "sensación" de equilibrio económico a partir de un paquete de estrategias mediáticas que estuvieron orientadas a la diferenciación del territorio a partir de lo que denominamos como mitos de gobierno en tanto "marcadores discursivos" de las transformaciones territoriales realizadas en el espacio.

Un ejemplo paradigmático de lo anteriormente expuesto se puede apreciar en la campaña publicitaria divulgada en el verano del 2003 gobernación de Alicia Leme-que promocionaba a la provincia como otro país en el marco de los efectos estructurales del grave contexto económico y político a nivel nacional. En este sentido, coincidimos con Trivi (2014) en reconocer que la idea de otro país se introduce "como metáfora de un estilo de gestión, de administración de un territorio, que se contrapone a lo que sucede a nivel nacional" (p. 9). La idea de progreso que converge con la fantasía - provincia sin desempleo y pobreza- y lo tecnológico serán vectores que harán del territorio provincial una usina de innovación en materia de infraestructura tecnológica e innovación digital.

En 1998 la gobernación firma un convenio con el Ministerio de Canadá para la producción en conjunto de un Plan Maestro de la Autopista de la Información, considerado como el primer paso para la constitución de una agenda digital. Este proyecto se implementó en 2001 - mediante una licitación pública e internacional - a partir de la generación de una red de comunicaciones para gran parte de la extensión territorial. En este sentido, la provincia en las últimas décadas se ha convertido en un "modelo de desarrollo digital" a partir de distintos programas que han acentuado la importancia de la informatización como aspecto clave para el desarrollo y progreso de los territorios. Las denominadas "autopistas de la información"14 (AUI) han sido consi-

14 Una entrada posible para repensar estos entramados de producción de "sujetos innovadores" sería una lectura de la producción de escenarios de concientización/pedagogización en torno al uso de las tecnologías y a "lo digital" como camino de desarrollo y progreso. Esta "afluencia" digital en los territorios que integran el mapa provincial -y 
deradas un hito para la provincia, caracterizadas por tecnologías que no están ancladas geográficamente, sino que se expanden en el territorio y crean puntos de atracción de inversiones nacionales y privadas en toda la provincia. Este sistema se encuentra desarrollado sobre "un tendido de fibra óptica y radioenlaces propios, primordialmente una plataforma de infraestructura de telecomunicaciones y servicios de acceso común" (Finquielievich et al., 2013, p. 25).

Este modelo "digital" de gubernamentalidad dirige sus acciones a la cobertura de infraestructura tecnológica basada en autopistas, data center, y el despliegue de una red antenas wi-fi en toda la extensión de la cartografía urbana. En este contexto, resulta importante mencionar la creación de la ciudad de La Punta (fundada en el año 2003) como epicentro del "conglomerado digital" donde se erige el data center considerado el "cerebro y los brazos" de la autopista ${ }^{15}$. Se trata de "caminos virtuales" que enlazan puntos geográficos a partir de lo tecnológico y que intentan tender puentes de acceso para la oferta de contenidos culturales/simbólicos de la red, en tanto nuevo espacio que modula las prácticas y sentidos de los habitantes de la ciudad. Estas reestructuraciones de los territorios a partir de lo tecnológico son denominadas por el gobierno provincial como "localidades wifi", cuya funcionalidad radica en la "integración/inclusión" de los ciudadanos vía digitalización de la información. Este aspecto se materializó poco después en el Derecho a la Inclusión Digital, incorporado a la Constitución Provincial en el año 2011 y que otorgó un marco legal a las intervenciones

especialmente la ciudad capital- están también complementados por políticas ligadas a lo educativo, mediante la difusión y apropiación de las poblaciones de contenidos interactivos y acceso a redes inalámbricas de internet, a modo de "inclusión" de los habitantes dentro de cierta circulación informacional como rasgo modernizante del nuevo siglo. En este sentido, mencionamos el Plan de Inclusión Digital para la producción de escuelas destinadas al impulso del desarrollo digital y alfabetización en el manejo de las nuevas tecnologías.

15 Es considerado como el centro tecnológico más moderno de América del Sur. En el mes de agosto del año 2019 fue elegido entre los cuatro nominados para el premio internacional Data Center Dynamics para la categoría "Mejor Prestación de Servicios Digitales en el Sector Público” en la ciudad de México, D. F. (Diario de La República, 2019). Resulta interesante destacar que en tanto "lo digital" sea considerado como "el cerebro y los brazos" de toda una economía de innovación no se deben perder de vista las consecuencias estructurales en torno a la dinámica de trabajo regulada por vía informatización. En este sentido, como contraparte, destacamos la falla ocasionada por el robo de datos en el Data Center a principios del mes de diciembre de 2019, donde el ciberataque obstaculizó el cobro de salarios de planteles docentes provinciales (El Chorrillero, 2019). 
realizadas por el gobierno en la instalación de más de 1.381 antenas wifi distribuidas en toda la provincia ${ }^{16}$.

Este modelo de desarrollo, dirigido a la digitalización e informatización de las sociedades en torno al acceso abierto - y de los territorios-, posee como doblez el control/regulación de la circulación de la información y de los cuerpos. La circulación y la detención se complementan en este plano para conformar fronteras simbólicas y materiales a cielo abierto, donde los sujetos se convierten en objeto de regulación vía control y vigilancia de los movimientos, como del conjunto de elementos y dinámicas que atraviesan los espacios urbanos: circuitos, desplazamientos, cuerpos, mercancías y bienes culturales y/o materiales. Así, lo digital - en tanto vía de desarrollo- enmarca políticas activas ligadas al control y a la monitorización de los movimientos carreteros y pedestres, posibilitada por la expansión de tecnologías de vanguardia aplicadas en la superficie de los territorios; por "debajo" - a partir de redes inalámbricas que fluyen como ríos de información-y "por arriba" por medio de modernos circuitos de autopistas ${ }^{17}$.

En un sentido convergente, referimos a las políticas de seguridad y vigilancia - cuyos alcances se encuentran anclados y desanclados a "lo digital" - que han reordenado el espacio y los movimientos que la atraviesan desde distintos puntos de la cartografía urbana. Seveso (2018) realiza un análisis profundo en torno a las políticas de seguridad, estableciendo puentes interpretativos con las modalidades de gestión territorial en la ciudad en los últimos años. Siguiendo esta clave de lectura, el autor postula que existen marcadas relaciones en torno a la dinámica urbana y sus transformaciones y las políticas de seguridad implementadas. Las implicancias de las estrategias ligadas al control policial en el territorio se enlazan en objetivos referentes a la conservación de la "unidad sistémica", antes que en la comprensión

16 Se presume la incorporación de 150 antenas más con capacidad de wifi 3.0 para conectar localidades que posean una mayor afluencia turística. Entre ellas se encuentran: Buena Esperanza, Candelaria, Carpintería, Concarán, Luján, El Trapiche, La Toma, Juana Koslay, Potrero de Funes, Justo Daract, Merlo, Nueva Galia, Naschel, Quines, San Francisco, Santa Rosa, Tilisarao, y Unión. Según el gobierno provincial, las antenas proveen a las "localidades wifi" de un rendimiento de acceso de hasta 90 veces mayor velocidad (Diario de La República, 2017).

17 Desarrollaremos más adelante el moderno sistema de autopistas de la provincia, entendiendo que este elemento se encuentra ligado a otro tipo de transformaciones territoriales que articulamos en la figura de la "ciudad turística". 
de las causas de "lo delictivo", atacando de manera directa los focos conflictivos que ponen en riesgo la libre circulación de la mercancía y la generación de valor. Así, las políticas de seguridad - junto con otras políticas sociales- operan en las formas de estar/ser, tensionando el par cuerpo/clase que se mueve, desplaza y reproduce en distintos escenarios de conflictividad emergentes (Seveso, 2018).

En esta dirección, las políticas de seguridad se convierten en un eslabón clave para la comprensión de las condiciones de estructuración de la ciudad a partir de la necesidad de preservación de un determinado orden urbano, caracterizado por una tecnología de vanguardia puesta para regular la condición esencial del funcionamiento de los regímenes de acumulación urbana: la movilidad. Si situamos esta clave de lectura para la configuración de San Luis advertiremos, a partir de los estudios de Seveso (2018), que la fuerza de seguridad puntana ha tendido en los últimos años a una creciente diversificación de sus servicios de control, extendiéndose a mecanismos de disciplinamiento ${ }^{18}$ que incluso interpelan a la población local en tanto "extensiones" de sus roles de control y seguridad ${ }^{19}$.

Resulta importante mencionar esta diversidad en el despliegue de la fuerza policial que se extiende a áreas diversas y funciones que en su superficie aparentan ser disímiles, tales como: la "Policía Caminera" y el control de las rutas provinciales, la "Policía Ecológica" destinada

18 Seveso (2018) realiza una descripción detallada de las acciones institucionales que crearon los "marcos legales" para la implementación e intensificación de las políticas de seguridad en el territorio provincial. Se destaca la puesta en vigencia de la Ley $\mathrm{N}^{\circ} 5.018$ de Cuadro Único Policial que permitió la nivelación y profesionalización de los agentes policiales. Esta medida habilitó la creación de distintas instituciones formales educativas, así como carreras de especialización para fuerzas policiales de la ciudad. En 2006, a partir de la Ley de Emergencia en Seguridad, las modalidades de acción policial toman un giro significativo a partir de la creación de nuevas dependencias policiales. En 2017 se elimina el "cuadro único policial", diversificando la carrera profesional e intensificando la formación a partir de cursos obligatorios en áreas tales como niñez, adolescencia, juventud, medioambiente y turismo.

19 Esta incorporación de la sociedad civil a la fuerzas de seguridad corresponde a una estrategia de "socialización y democratización" de la problemática de la seguridad, tendiente a involucrar a los ciudadanos a las instancias de "diseño, aplicación y gestión" de las políticas de seguridad a partir del Programa de Concertación con la Comunidad (PCC). Este proceso de inserción de las comunidades a funciones de control y regulación de la conflictividad territorial es comprendido por Seveso y Lisdero (2013) en el marco de estrategias de "securitización y policiación ciudadana" caracterizadas como "un proceso de dosificación de las competencias de control, regulación y represión más allá de marcos institucionales cerrados y definidos" (p. 111). 
a la protección de los recursos naturales, la "Policía de Turismo" para la preservación de actividades turísticas y comerciales y la "Policía de la Juventud" destinada a las poblaciones de "edad vulnerable" frente a temáticas relacionadas con la drogadicción y deserción escolar (Seveso, 2018). A menudo, estas áreas se combinan en los distintos megaoperativos policiales que se realizan en puntos denominados como estratégicos, debido al registro de hechos delictivos en zonas barriales marcadas por los mapas del delito. El uso de cámaras distribuidas en toda la provincia (450 en total durante el año 2016) facilita la detección, control y vigilancia de las prácticas de los ciudadanos y sus desplazamientos. En este sentido, resulta importante mencionar la creación del Centro de Control de Cámaras (2016), dependiente del Ministerio de Ciencia y Tecnología, que en conjunto con las fuerzas policiales actúan vigilando y regulando cierto "orden de la ciudad". Su implementación favoreció el nucleamiento de los servicios de vigilancia y control centralizados actualmente en las oficinas de las "Terrazas del Portezuelo" donde se disponen múltiples espacios y computadoras para monitoreo. A la puesta en funcionamiento de las cámaras se suma la adquisición de drones, constituyéndose una de las herramientas tecnológicas de mayor innovación en el servicio de seguridad de la provincia. Los drones "capturan imágenes en alta resolución, las que se pueden utilizar para obtener registro de situaciones vandálicas o delictivas ... estos dispositivos pueden trasladarse a cualquier lado, movilizarse sin problema y ser útiles para alguna circunstancia especial" (Catalfamo, ANSL, 2014). Los drones adquiridos por la provincia fueron implementados no solo para captación de hechos delictivos, sino también para sobrevolar y obtener registros fotográficos y transmitir en tiempo real la realización de grandes eventos culturales y deportivos, como el Carnaval de Río en Potrero de Funes.

Este control de los desplazamientos se sitúa en dos planos diferenciales. Uno de ellos ligado al control y vigilancia pedestre fuertemente enraizado en el monitoreo activo de los espacios barriales y el desplazamiento de sus habitantes a partir de prácticas "securitarias" — a decir de Seveso- relacionadas con el patrullaje barrial/territorial ${ }^{20}$. En un

20 Estas prácticas de vigilancia territorial estuvieron posibilitadas a partir de la creación del Centro de Control Operativo y el Sistema de Vigilancia Urbana basados en la implementación de cámaras digitales e innovadores dispositivos electrónicos para la 
segundo plano, encontramos las acciones destinadas a la monitorización carretera tendientes a vigilar las entradas y salidas de la ciudad capital, así como los accesos a las unidades territoriales satélite como Juana Koslay y/o Potrero de Funes. En 2017, por ejemplo, el gobierno implementó un moderno sistema digital para el control de patentes en las distintas autopistas y rutas de la provincia, que denominó Sistema Electrónico de Patentes. Este innovador dispositivo de identificación y control cuenta con cámaras de seguridad, sensores situados en los caminos y una pantalla LED donde se visualiza la patente del vehículo que circula, además de capturar fotográficamente el movimiento del rodado. Esta modalidad de "seguimiento vehicular" se aplicó en un primer momento para los móviles del estado provincial hasta extenderse a "flotas de movilidades dependientes del municipio o de empresas de transporte público de pasajeros (...) la configuración de los equipos define a qué dirección IP se dirigen, y cada cuánto tiempo se transmite (...) con una frecuencia de 5 segundos por móvil (Da Rold y Munizaga, 2010, p. 37). En 2010 la suma de móviles que transmitía esta información ascendía a 250 y se presume que esta cifra puede haber aumentado en los últimos años. Esta es una de las formas de controlar la movilidad a partir de dispositivos tecnológicos desplegados para el policiamiento de los desplazamientos.

El gobierno ha comprendido que "en la geolocalización está la clave", como enuncia en uno los informes realizados por la Universidad de La Punta en torno a las denominadas "tecnologías de posicionamiento" aplicadas al territorio provincial, donde es "posible modular el mundo real y con él, la posición de las cosas" (Da Rold y Munizaga, 2010, p. 12). Así el modelo de San Luis Digital es motorizado por políticas de acceso e inclusión digital que actúan como doblez regulando y monitorizando los movimientos de los cuerpos, las mercancías y la circulación de la información, los que como observamos también se constituyen en elementos que integran una activa política de regu-

detección e identificación de hechos delictivos. En este sentido, mencionamos la plataforma digital Vecinos en alerta que permite al usuario subir información geoespacial para la conformación de un mapa del delito que contendrá "zonas calientes/clústeres del delito" de los espacios barriales a partir de una cuantificación de las ocurrencias delictuales. Este dispositivo permite la marcación de determinadas zonas en el mapa de la ciudad que influyen en los operativos policiales (operativos saturación/desplazamiento por saturación) en distintos puntos de la ciudad. 
lación de las interacciones. Resulta entonces importante discutir la caracterización de este modelo de desarrollo digital que se presenta en el plano discursivo, estableciendo un trayecto que parte "desde la periferia geográfico-económica hacia el centro" ${ }^{21}$, pero que en el plano material refuerza las distancias e incrementa el carácter extractivo del patrón de acumulación y riqueza que responde a un único "centro". En este sentido, los modelos de gestión implementados en el marco de políticas de corte neoliberal no han podido incluir a las capas más vulnerables más allá de los voluntarismos y deseos expresados en el plano discursivo de las intervenciones estatales diagramadas. Asimismo, estas desigualdades se traducen en el plano espacial a partir de la producción de escenarios contrastantes donde las brechas entre ricos y pobres quedan materializadas en las condiciones de habitabilidad diferenciales que consideramos expresiones naturales del pretendido desarrollo.

\section{La "ciudad turística"}

Hemos observado que en los últimos años la ciudad de San Luis ha implementado una activa política para gestionar y preservar la circulación de las ideas y haceres prácticos de una gubernamentalidad que define las maneras de nombrarla y percibirla: "San Luis, es la llave", "San Luis, otro país" en tanto marcas de fantasía que acompañan la oferta de imágenes y transformaciones territoriales a gran escala. Estas transformaciones han evidenciado una orientación intervencionista que enfatiza la "espectacularización" y la monumentalidad de las construcciones, privilegiando la exaltación de las experiencias de los transeúntes y de los visitantes que arriban a la ciudad alimentados por los "mitos de gobierno" en torno a las exitosas políticas industriales y al aparente equilibrio económico de la provincia.

21 "Gobernar desde la periferia al centro" se ha convertido en una premisa de campaña y de gestión en la gobernación de Alberto Rodríguez Saa. Estas palabras son pronunciadas en cada una de las inauguraciones de obras y/o infraestructuras adquiridas o apariciones públicas del gobernador frente a los medios. Las correlaciones espaciales de este modelo de gestión se traducen en la creación de "Terrazas del Portezuelo" - centro administrativo y de gobierno de la provincia- que representa su expresión material en la medida que la infraestructura se encuentra emplazada a las afueras de la ciudad como símbolo de esta modalidad de gobernación que interviene desde la periferia hacia el centro. 
Manejamos una premisa que nos orienta a pensar en las transformaciones generadas por el turismo - como una de las vías de desarrollo consolidadas en los últimos años- a partir de los rasgos modernizantes que observamos en las obras de infraestructura emplazadas para su contemplación en distintos puntos del territorio. Así, creemos que los impactos socioambientales que producen las políticas de turistificación en los espacios inciden en las tendencias de estructuración de la ciudad donde se consolidan ciertos "entornos" a partir de la concentración de grandes infraestructuras en zona de serranías e intensifican la fisonomía de fragmentación inter-intraclases en el interior de los territorios (Boito, 2013). Veamos cada uno de estos aspectos que involucran estas tendencias que, capilarmente, aparecen como puntos fragmentarios, pero que se convierten en lugares relacionales para pensar las dinámicas de transformación material/sensible de los espacios.

A partir de 2010 se impulsan numerosas obras arquitectónicas que "remodernizaron" la ciudad e incidieron en las dinámicas territoriales construidas durante la etapa industrial. Estas transformaciones están enmarcadas en una fuerte política turística e impulso digital (en sintonía con los planes federales desarrollados a nivel nacional ${ }^{22}$ ) que demandaron una marcada presencia estatal en el territorio. En este sentido, las tendencias de intervención de la gubernamentalidad provincial registrarán importantes inversiones en el sector del turismo donde existirá

una marcada expansión cuantitativa y cualitativa ... ya sea por el aumento de las plazas y establecimientos hoteleros, de las visitas nacionales e internacionales, como por la diversificación y la jerarquización de destinos para una variada demanda del turismo asociada a nichos. (Trivi, 2014, p. 4).

22 Durante la década del 2000 hubo una importante intensificación de las políticas turísticas a nivel nacional. Trivi (2014) realiza una reconstrucción de las distintas medidas implementadas, durante el periodo del kirchnerismo, asociadas al turismo en la Argentina. Analiza los impactos territoriales de las medidas aplicadas - en el marco de la Ley de Turismo (2005) y la creación del Ministerio de Turismo (2010) - la implementación de distintos planes federales estratégicos para la intervención de los territorios. El autor se centra en las transformaciones territoriales evidenciadas en la provincia de San Luis a partir de estos periodos de fuerte impulso turístico destacando actores, hechos y visiones de territorio que subyacen a las políticas implementadas. 
Así, el gobierno provincial sanciona en el año 2010 la Ley General de Turismo-Plan Maestro de Turismo 2010-2020 donde se declara al turismo como "política prioritaria y estratégica para el progreso y la inclusión económica-social" (Ley NVIII-0722-2010, artículo 1º). La inserción de la dinámica turística como vector para la promoción-económica y social de la provincia produjo reordenamientos en las inversiones públicas en infraestructura orientadas al montaje de escenarios de monumentalidad en distintos territorios. En 2010, a partir de los festejos del Bicentenario de la Patria, se construye la "réplica" del Cabildo de Buenos Aires que recrea morfológicamente las características arquitectónicas de la antigua construcción del siglo XIX en la ciudad de La Punta, ubicada a pocos kilómetros de la ciudad capital. La réplica cuenta con recovas, bóvedas y muebles que respetan las condiciones primigenias de la construcción original, construyendo una imagen similar al cabildo histórico de 1810. Asimismo, fue edificado en la misma ciudad el estadio "Juan Gilberto Funes" para eventos deportivos y gastronómicos y el Data Center como parte del auge de las autopistas de la información. Se suman a este conjunto de edificaciones vanguardistas el Autódromo Semipermanente de Potrero de los Funes ${ }^{23}$, el Parque Astronómico y la promoción de distintos eventos que ubican a la provincia en el escenario nacional (por ejemplo El carnaval de Río en San Luis y las carreras de automovilismo en el circuito semipermanente de Potrero de Funes en el marco del Turismo carretera).

Figura 2.

\section{"Hitos urbanos" de la ciudad}
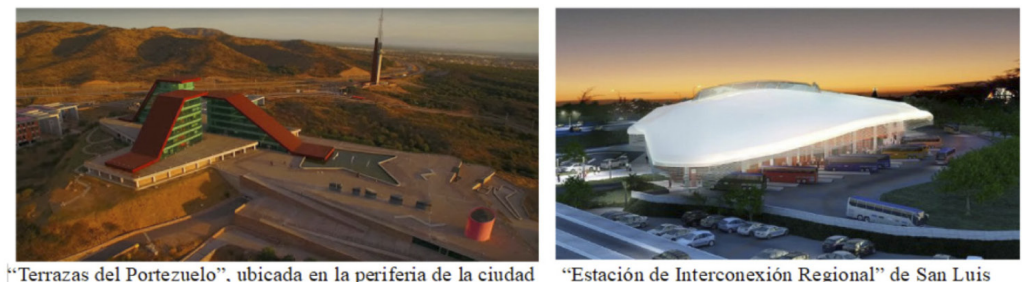

"Estación de Interconexión Regional" de San Luis

Fuente: ANSL (2014)

23 En el caso del autódromo, "su construcción implicó la deforestación de miles de metros cuadrados; la alteración del hábitat de especies animales y vegetales debido a las grandes remociones de suelo, sin tener en cuenta la topografía e hidrografía locales; la profunda transformación del ritmo de vida de los pobladores locales, algunos de los cuales incluso sufrieron la expropiación de sus tierras" (Trivi, 2014, p. 7). 
La monumentalidad de las construcciones resulta característica de estas políticas que tienden a la revalorización y embellecimiento de los espacios urbanos. Incluso, las infraestructuras construidas para la potenciación del turismo son relacionadas con obras públicas que enmarcan otro tipo de funciones. Mencionamos en este aspecto la construcción de la casa de gobierno denominada "Terrazas del Portezuelo", considerada una obra "faraónica" por los medios locales que alberga los distintos ministerios provinciales. La arquitectura presenta la morfología de una pirámide escalonada y se encuentra emplazada en lo alto de un cerro y distante del área céntrica conectada por medio de autopistas. Se suma la moderna terminal de ómnibus denominada Estación de Interconexión Regional de Omnibus inaugurada en 2012 durante la gobernación de Claudio Poggi. Durante su apertura el gobernador señalaba el carácter de "paso" que había confinado a la provincia a su relegamiento dentro del mapa de decisiones a nivel nacional. Sin embargo, en sus declaraciones aseveraba que esta percepción estaba cambiando a partir de la construcción de atractivas y modernas infraestructuras de vanguardia. En este sentido la nueva terminal fue considerada un "hito urbano" en proximidad y cercanía con otra "marca" de desarrollo y progreso de la ciudad como Terrazas del Portezuelo ${ }^{24}$. La característica común de estas construcciones monumentales refiere a que no solo albergan funciones ministeriales y/o de transporte, sino que también comprenden actividades culturales potenciales de ser promovidas turísticamente. Podemos mencionar, la serie de pop art montada en el salón del centro cívico en 2011 y que estuvo caracterizada por la exhibición de caballos de fibra poliéster de tamaño natural, pintados por reconocidos artistas plásticos del país, entre ellos: Marta Minujín y Milo Lockett. En este sentido, las estrategias de valorización asociadas al turismo están relacionadas con la promoción de "lo monumental", que sirve como captura de las inversiones públicas y privadas de la oferta turística a nivel nacional, así

24 "Desde lo turístico, este edificio pasará a ser un nuevo hito urbano que se complementa con proximidad con otro hito como lo es Terrazas del Portezuelo, siendo una visita obligada del visitante, del turista, generando más horas de visitas, más días en nuestra provincia, además de nuevas oportunidades de trabajo y también contribuirá a descongestionar el tránsito, brindando mayor fluidez, conexiones más dinámicas y trasbordos rápidos para hacer más eficiente el servicio de transporte" (Claudio Poggi durante el acto de inauguración de la nueva terminal de la ciudad de San Luis) (ANSL, 2012). 
como en el sostenimiento de una imagen idealmente promovida de la provincia y sus destinos. Resulta importante mencionar que el emplazamiento de estas grandes construcciones se encuentra distante de los centros urbanos y muy cercano a la red de autopistas desplegadas para la mayor movilidad de bienes y mercancías. No es un dato menor que San Luis contenga el $40 \%$ de las autopistas construidas en la Argentina. En este sentido, la utilización de automóvil personal para el acceso a lugares, paisajes y recorridos que ofrecen este "sistema-red turísticos" resulta un elemento prioritario para la participación de las poblaciones en las experiencias que ofrece el mercado del turismo en la provincia. Es destacable mencionar también que los intereses gubernamentales estuvieron orientados a desmitificar la percepción de que "San Luis es solamente un lugar, con una geografía linda. Un lugar de paso. Hay que corregir el falso rumbo. San Luis es un destino" (Conferencia pronunciada por Alberto Rodríguez Saa 1998 en la inauguración del Centro de Estudios Sociales).

El territorio como destino, punto de principio y llegada, han sido vectores de las intervenciones que remodelaron el paisaje de una provincia que ha sido considerada en sus comienzos expulsógena de habitantes por la falta de atractivo e impulso a sus economías agrarias locales. En este sentido, las lógicas de valorización de los espacios condensadas en la figura de la "ciudad turística" nos refiere a la activa producción de "circuitos/caminos de experiencias promovidas idealmente", donde la autopista permite la contemplación fugaz de monumentalidades ubicadas estratégicamente en sus bordes para la conformación de puntos de encuentro/puntos de distancia en el acceso de bienes simbólicos y culturales como en las experiencias que se entretejen vía movilidad mercantil (experiencias y bienes). Esta "redcircuito de experiencias y lugares" está caracterizada por zonificaciones socio-residenciales a partir de las articulaciones que establece con las ciudades de Juana Koslay, Potrero de Funes y La Punta, las que han adquirido lógicas propias a partir del incentivo turístico y tecnológico aplicado en los últimos años.

En simultáneo al nucleamiento de importantes intervenciones territoriales y modernas infraestructuras para fines gastronómicos, culturales y de entretenimiento se suma el aumento de movimientos socio-residenciales en el interior de estas ciudades que conforman el 
conglomerado San Luis- El Chorrillo. En estas ciudades satélites se concentran los estratos altos; sus desplazamientos y decisiones de residencia, mientras que los sectores sociales bajos permanecen en la periferia de la ciudad capital bordeando el río y/o barrios sociales construidos a partir de políticas habitacionales durante los periodos de promoción industrial aplicados en la provincia. Coincidimos con Seveso (2015) en definir estos espacios como lugares de "transición entre el campo y la ciudad en los que se mezclan los usos del suelo y las formas de vida rurales y urbanas" (p. 10), donde la capital ocupa un lugar predominante como centro de dinámicas políticas, administrativas y financieras.

Resulta importante destacar que el centro histórico de la ciudad de San Luis no ha tenido importantes intervenciones con rasgos de monumentalidad como lo evidencian otros puntos del territorio provincial. Esta diferenciación se relaciona con las modalidades de intervención del gobierno de la provincia caracterizadas por un perfil "desterritorializado" que construye circuitos experienciales en distintos puntos del territorio, a diferencia de los alcances del gobierno municipal que hasta 2020 responde a un sector político-ideológico diferente. Entre las intervenciones de revalorización y embellecimiento de la ciudad de San Luis mencionamos la política de peatonalización de las principales calles de la ciudad implementada por el municipio en el año 2012. Dichas modificaciones fueron realizadas en la calle Rivadavia, una de las principales vías céntricas de la ciudad (Vía Rivadavia). Asimismo, mencionamos las recientes obras realizadas en la última década, tales; como la renovación del Paseo del Padre y el puente peatonal Lafinur - Puente de la Familia-como obras que por un lado vinculan espacios y zonas de la ciudad y, por otro, habilitan alternativas de desplazamiento. De esta manera, el polo comercial y turístico de la ciudad de San Luis queda comprendido en las cuatro avenidas principales (Avenidas Illia, Roca, España y Lafinur) que demarcan el espacio del casco histórico. Por otra parte, las actividades recreativas y deportivas se concentran en torno a la costanera del río San Luis hacia el sur, que será revalorizado para la construcción de una zona residencial a lo largo de sus márgenes ${ }^{25}$.

25 Las acciones de revalorización del Río San Luis se enmarcaron en el proyecto Parque Costanera Río San Luis, cuyos objetivos se centraron en la creación de un eje descentralizador de la ciudad, siguiendo el curso del río hacia el sur. La obra fue considerada como un "nuevo paradigma urbano" y espacio de despliegue de actividades 
Estas transformaciones para la revalorización del centro histórico están enmarcadas en el Plan Maestro "Neo San Luis 100\% Confortable" presentado en el inicio de la intendencia de Enrique Ponce. Dicho plan de desarrollo urbano consigna distintas acciones estratégicas para la modificación e intervención de los espacios, así como también una visión proyectiva de las transformaciones de la ciudad que impulsará el gobierno en los próximos años. En el proyecto se definen los roles asumidos por la ciudad caracterizándola en: Ciudad Administrativa, Ciudad Industrial, Ciudad Universitaria, Ciudad Turística, Ciudad de Conexiones y Ciudad Comercial. Esta proyección del municipio en la diagramación de varias ciudades en una permite identificar las características que se imponen en las últimas décadas y los desafíos delineados por el gobierno para los próximos años. La proyección de una ciudad compacta está caracterizada por áreas delimitadas a partir de una redistribución del uso del suelo con concentraciones de polos de desarrollo en distintos sectores de la ciudad, para albergar actividades empresariales, administrativas y financieras en la zona oeste de la ciudad, donde se concentra la mayor parte de asentamientos urbano-informales.

Figura 3.

San Luis del Futuro

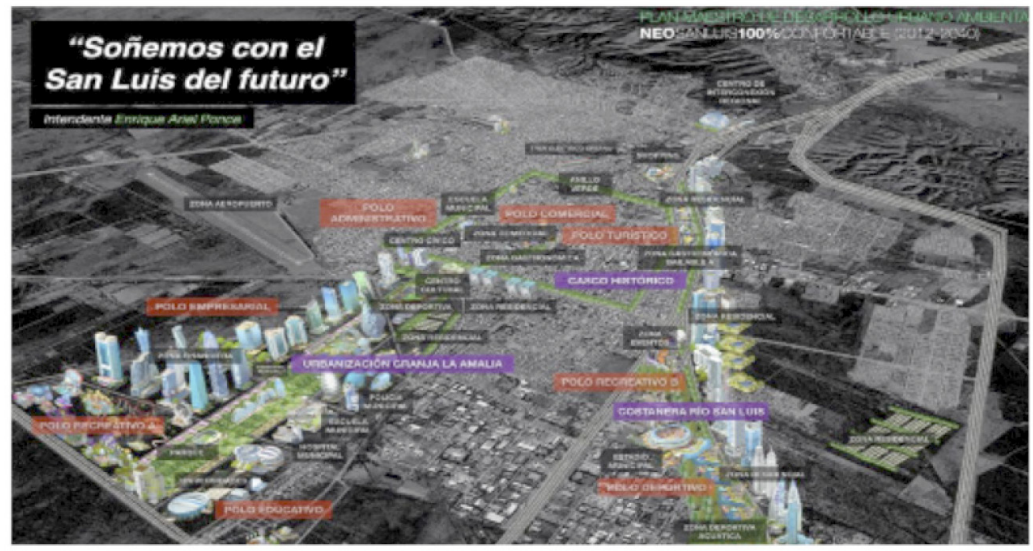

Fuente: Plan Maestro de Desarrollo Sustentable Urbano Ambiental “Neo San Luis 100\% Confortable" (2012-2040).

comerciales, culturales, sector de hotelería y salud además, de un polo gastronómico (Ministerio de Obras Públicas e Infraestructura, ANSL, 2016). 
Estas políticas dirigidas a la revalorización de los espacios tienden a "contentar-contener" a los vecinos a partir de la puesta en color de sus espacios barriales - y de sus vidas cotidianas- como parte de una estrategia vía turistificación, que intenta incluir "barriadas" que presentan diversas problemáticas en sus infraestructuras y obtener "valor/ plusvalía urbana" para la montada imagen de ciudad ${ }^{26}$. En este sentido, la producción de entornos es impulsada por estas intervenciones dirigidas a la valorización y embellecimiento —explotación- de los espacios, al mismo tiempo que "las condiciones de protección constituyen una arena fundamental que cementa el acceso a 'experiencias' mercantilizadas" (Seveso, 2018, p. 103).

El caso del programa "Pinta San Luis", perteneciente al Ministerio de Obras Públicas e Infraestructura, se relaciona con estas intervenciones orientadas de manera directa al embellecimiento de los espacios. La iniciativa propone la "puesta en valor" y la "renovación/revalorización" de edificios históricos, puentes, parques e incluso distintos barrios populares de la ciudad gracias al oficio de artistas locales, trabajadores de planes sociales y vecinos de la ciudad. La acción de "poner color" a zonas relegadas para embellecerlas e integrarlas — al menos en su fachada - al movimiento de desarrollo y al progreso de la provincia se convierte en un mecanismo de reconexión social para superar la polarización establecida en décadas anteriores.

26 Destaca el ministro de Obras Públicas, Tomasevich: "Lo que esto genera es que la misma gente del barrio empiece a cuidar más cada lugar, ya no se ven tachaduras ni grafitis, es lo mismo que en su comienzo se hizo en los puentes y autopistas, que hoy por hoy se siguen conservando en muy buen estado. La idea es continuar con los demás barrios. Queremos darle más color y más belleza a la ciudad de San Luis, cambiar la apariencia y la vista de cada zona. Eso atrae más miradas, despierta interés, eso es lo que quiere el gobernador". En consonancia con estas palabras, los vecinos de los barrios intervenidos para su embellecimiento comentan que: "vivimos con alegría y emoción que esta vez nos tocó a nosotros. Se está haciendo un gran trabajo. Tengamos en cuenta que el lugar es amplio y es difícil pintar los edificios dadas sus condiciones. Los vecinos estamos felices" (ANSL, 2019). 
Figura 4.

Barrio "embellecido" de la periferia de la ciudad

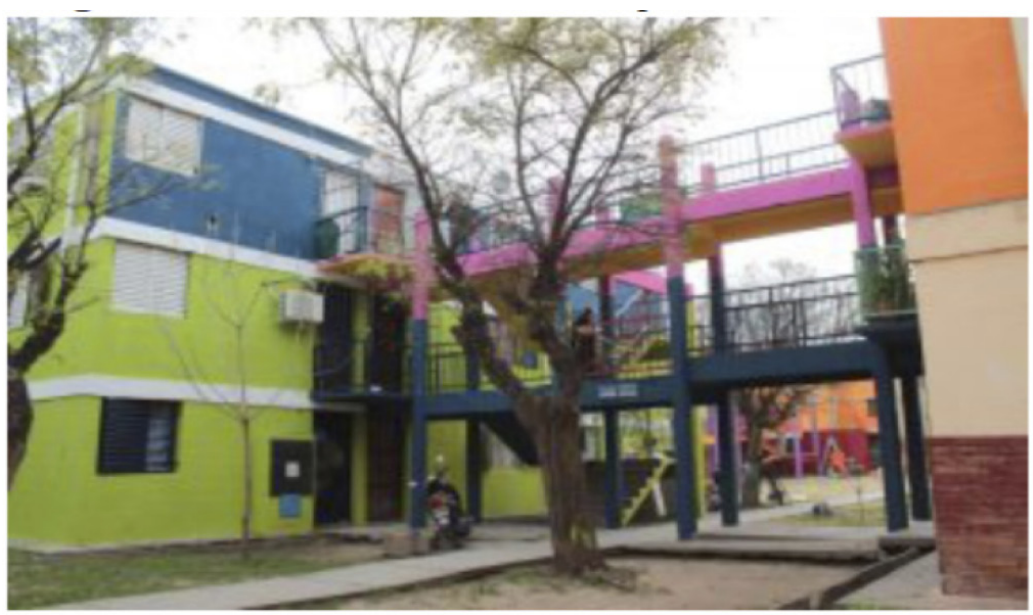

Fuente: ANSL(2019).

Así, los objetivos de las políticas turísticas del gobierno están orientados a tres aspectos relacionados con la valorización patrimonial, el desarrollo del espacio, la oferta turística y al estímulo de las inversiones turísticas que pretenden involucrar la participación ciudadana, la búsqueda de la sustentabilidad y el cuidado por el medio ambiente. Sin embargo, Trivi (2014) afirma que estas "búsquedas y buenas intenciones de gobierno" solo quedan expresadas en un plano discursivo sin expresiones tangibles y materiales en la realidad. En este sentido, argumenta que "las fuertes intervenciones en el territorio provincial tienen un impacto social y ambiental que pone en jaque la pretendida sustentabilidad del proceso, así como pone en duda el alcance de la participación ciudadana que lo refrenda" (p. 5).

Es posible afirmar que estas políticas se intensificarán a partir de las modulaciones sensibles que promete la asunción de la tercera gobernación de Alberto Rodríguez Saá (2020-2024) cuando sostiene que "cada cosa de cemento viva con el corazón de la puntanidad" donde "le vamos a poner alma" (Agencia de Noticias San Luis, 09/12/2019, ANSL). Esta proyección del "San Luis del cemento" ${ }^{27}$ que pondrá alma

27 Para ver el discurso de asunción completo del mandatario: http://agenciasanluis. com/notas/2019/12/09/mensaje-completo-del-gobernador-alberto-rodriguez-saa/ Como complemento, se ha difundido recientemente el spot oficial del acto de asun- 
a la ciudad a partir de la argamasa resulta interesante para tensionar esa imagen que Sennett (1997) nos traía en torno a la "carne y la piedra", donde las sensaciones (tocar, oler, moverse) se encuentran reguladas y asociadas con la forma/construcción de las ciudades. En este caso, dar alma al cemento de la ciudad y a la puntanidad trasciende la misma carne para dar vida - directamente - a los cuerpos, a los espacios y al cemento por donde se desplazan.

\section{Conclusiones}

Este artículo supone un primer esfuerzo en la comprensión de la dinámica compleja que atraviesa a una ciudad latinoamericana de escala media y del interior del sur periférico global. Para ello, revisamos, en primer lugar, algunas características generales de los espacios urbanos intermedios como lugares de innovación y experimentación de distintos modelos productivos. Sostuvimos que los rasgos distintivos de estas ciudades se encuentran relacionados con la intensificación de los flujos y circuitos capitales característicos del sistema de acumulación actual.

En este caso, la noción de movilidad tomó un lugar relevante en el recorrido que planteamos, en la medida que los espacios urbanos intermedios son caracterizados por la potenciación de los desplazamientos y el tendido de circuitos y redes por fuera y dentro de sus áreas de influencia, así como las formas que asumen sus espacios. La "condición circulatoria" (Camarena, 2013) de las ciudades atraviesa cada uno de los montajes de desarrollo y en sus implicancias espaciales traducibles en escenarios urbanos diversos. En consecuencia, son espacios que tienden a ser controlables y gestionables a partir de un determinado proyecto y sentido de ciudad, los que direccionan las intervenciones territoriales como los flujos de personas y mercancías que atraviesan su órbita.

Bajo esta premisa, la ciudad de San Luis (Argentina) se convirtió en una clave de lectura para esta indagación. Observamos ciertas imágenes de desarrollo (ciudad industrial, ciudad digital y turística) cons-

ción de la nueva gestión denominado "Alma" enfatizando la asociación pronunciada por el gobernador entre el cemento - la ciudad - alma. https://www.youtube.com/ watch?v=UIVXaPBVK88 
truidas a lo largo de tres décadas, las que evidenciaron los impactos materiales y sensibles de distintas transformaciones espaciales, suscitadas al calor de determinadas tendencias productivas. De esta manera, intentamos establecer marcos temporales donde identificar algunos rasgos que fueron moldeando y caracterizando a la ciudad presente (y la del futuro). Los tres escenarios que planteamos son atravesados por una lógica de regulación del movimiento que vertebra la potenciación de los modelos productivos implementados por el gobierno provincial. Así, las "monumentalidades" que presentamos construyen un tendido de circuitos experienciales que moldean la provincia como destino turístico y/o las autopistas de la información que tras el discurso de la inclusión digital se apoyan en un sistema de control y monitorización de las interacciones y los desplazamientos de sus habitantes. Estas y otras imágenes se constituyen en fragmentos materiales donde empezar a enlazar aspectos de una totalidad urbana compleja y dinámica, en el marco de un contexto caracterizado por la proliferación de polos de desarrollo y pobreza. En este sentido, la zona del Gran San Luis (conformado por las localidades de San Luis, Juana Koslay, La Punta y El Volcán) refleja un índice de pobreza que ha aumentado en los últimos dos años, registrando un total de $39,2 \%$ de personas pobres y $6,3 \%$ de indigentes en el primer semestre de 2020 (INDEC, 2020). Teniendo en cuenta que estos datos se enmarcan en condiciones de intensificación de la regulación de los flujos mercantiles por la crisis sanitaria global que azotó a toda la población mundial, la desigualdad ha sido un continuum en estos escenarios urbanos, constituyéndose en expresiones y experiencias desiguales como correlato de las transformaciones espaciales impulsadas. Así, resulta importante mencionar que en consonancia con la construcción de ciertos regímenes de visibilidad en torno al desarrollo pujante del territorio provincial, la fragmentación socioespacial en la ciudad de San Luis se acentúa de manera creciente hacia el oeste, evidenciando condiciones de habitabilidad informales y precarias.

Pensar las desigualdades urbanas teniendo como prisma la movilidad supone comprender que en la diagramación de las ciudades existen dinámicas geográficas, económicas, culturales y políticas que influyen en los posicionamientos y desplazamientos de los objetos que las comprenden; : actores, objetos y procesos. Sin embargo, también consiste en reconocer que el movimiento - por antonomasia- es des- 
igual en la medida en que existen cuadrículas que se corren para que otros intereses prevalezcan, actores que "se mueven" y/o u otros cuerpos que permanecen sumidos en la espera. En este sentido, observamos los rasgos que ha asumido el espacio urbano a partir de la impronta de distintas tendencias productivas, las que poseen sus correlatos espaciales y que operan a través de políticas públicas que inciden en las posiciones sociales y materiales de los agentes y en las movilidades practicadas y/o reguladas dentro de la cartografía social.

En el caso de nuestra ciudad de estudio, la serie de transformaciones espaciales asociadas a las tendencias productivas desplegadas (industrial, digital y turística) habilitaron la emergencia de ciertos estados de conflictividad que atravesaron - y lo siguen haciendo- los escenarios urbanos que caracterizamos. La movilidad se convierte en un aspecto recurrente en estas intervenciones en el territorio en la medida que observamos cómo inciden en la reconfiguración de las distancias y proximidades existentes en la ciudad así como también en el control y monitorización de las circulaciones de bienes y servicios como y en los desplazamientos terrestres que las atraviesan.

No obstante, a en esta primera aproximación queremos destacar un señalamiento importante. Otorgar al movimiento un lugar omnipotente en la dinámica del orden urbano global es caer en el sentido común representativo del paradigma de lo fluido que sustenta el discurso posmoderno. Lejos de creer que el movimiento sea la llave maestra para descifrar la dinámica del sistema urbano mundial, lo consideramos un aspecto más que motoriza las formas que asumen las ciudades actuales. Desde un punto de vista analítico, corresponde a un lugar donde miramos y comprendemos las formas de producción del espacio urbano, las prácticas de los agentes y las políticas y técnicas que vigorizan y/o aletargan el desplazamiento de cuerpos y mercancías. Estos aspectos han sido un elemento de regulación constante por parte de los gobiernos, así como centro de disputa en la definición y en las maneras de vivenciar los espacios urbanos. Así, pretendimos tensionar subrepticiamente algunas imágenes celebratorias en torno al movimiento-transformación de las ciudades - tal es el caso del auge de las smart cities en la última década- como en los focos de conflicto y desigualdad que operan y acompañan el montaje de modelos de desarrollo en el interior de las ciudades de escala media, tal como es 
el caso de San Luis. Observar estas transformaciones corresponden es el punto de partida para construir una mirada de la ciudad que tenga como enfoque a la movilidad desde el cruce tensivotensional, recursivo y conflictual que supone la forma de estructuración de los espacios y los procesos de movilidad (políticas y desplazamientos).

De esta manera, este documento intenta ser un primer esfuerzo y aproximación a la comprensión de una ciudad latinoamericana del sur global, a la vez que un acercamiento a las dinámicas productivas que influyeron en su constitución presente. Como trasluz, una mirada al carácter dinámico de las ciudades en tanto plataformas para el movimiento y en las articulaciones conflictuales entre lo productivo y lo urbano que imponen las dinámicas circulatorias del capital.

\section{Referencias}

Arroyo, M. (2001). La Contraurbanización: un debate metodológico y conceptual sobre la dinámica de las áreas metropolitanas. Scripta Nova Revista Electrónica de Geografía y Ciencias Sociales, (97), http://www.ub.edu/geocrit/sn-97.htm

Becerra, M., Olguín, J., y Rodríguez, M.(2014). Asimetrías económicassociales en el interior de la provincia de San Luis en el contexto regional y nacional. Revista de Estudios Regionales y mercado de trabajo, (10), 93-122. http://sedici.unlp.edu.ar/ handle/10915/60104

Bellet, C. y Llop, J. (2004). Miradas a otros espacios urbanos: las ciudades intermedias. Scripta Nova. Revista Electrónica de Geografia y Ciencias Sociales, 8(165). http://www.ub.edu/geocrit/sn/sn-165.htm

Boito, M. (2013). Imagen, reproducción, entorno. Topos discontinuos en una reflexión estético-política. Revista La Trama de la comunicación,(17), 177-194. https://doi.org/10.35305/ lt.v17i0.425

Boito, M. y Espoz, B. (2014). Urbanismo estratégico y separación clasista, instantáneas de la ciudad en conflicto. Editorial Puño y Letra.

Busetti, M. (2007). Transformaciones en el empleo y el territorio: el caso San Luis. Revista de Estudios Regionales y Mercado de Trabajo, (3), 33-50. http://www.memoria.fahce.unlp.edu.ar/ art_revistas/pr.4335/pr.4335.pdf 
Camarena, M. (2013). Tres aspectos de las circulaciones de bienes prácticos y simbólicos de América. Diálogos Transdisciplinarios IV, Arte, Literatura y Sociedad. Universidad Autónoma de Querétaro, Querétaro, México.

Capel, H. (2009). Las pequeñas ciudades en la urbanización generalizada y ante la crisis global. Investigaciones Geográficas, Boletín del Instituto de Geografía, UNAM, (70), 7-32. http:// www.scielo.org.mx/scielo.php?script=sci_arttext\&pid $=\mathrm{S} 0188-46112009000300002$

Carrión, F. (2001). La ciudad construida. Urbanismo en América Latina. Facultad Latinoamericana de Ciencias Sociales, FLACSO.

Carrión, F. (2014). El regreso a la ciudad construida. En M. Millán y W. Brites (Comps.), Ciudades vivas, imaginaciones sobre el territorio (pp. 193-222). Universidad Nacional de Misiones.

Carman, M., Da Cunha, N., y Segura, R. (2013). Antropología, diferencia y segregación urbana. En M. Carman, N. Da Cunha, y R. Segura (Comps.), Segregación y Diferencia en la ciudad (pp. 11-34). Facultad Latinoamericana de Ciencias Sociales, (FLACSO), Consejo Latinoamericano de Ciencias Sociales (CLACSO) y Ministerio de Desarrollo Urbano y Vivienda. http://biblioteca.clacso.edu.ar/clacso/gt/20140707123234/ segregacionydiferencia.pdf

CELS (2003) Plan Jefes y Jefas $¿$ Derecho social o beneficio sin derechos? CELS. https://www.cels.org.ar/common/documentos/jefes_jefas.pdf

Da Rold, P. y Munizaga, A. (2010). Geoespacialidad, uno de los pilares de la web 3.0. La Punta: Universidad de La Punta. http://bpd. sanluis.gov.ar:8383/greenstone3/library/collection/material/document/HASH17al4cde548f55d5c2f998

Finquelievich, S., Feldman, P., y Fischnaller, C. (2013). Los territorios urbano-regionales como medio de innovación. San Luis ¿laboratorio ciudadano? Revista Iberoamericana de Ciencia, Tecnología y Sociedad, 8(23), 151-177. http://ref.scielo.org/ bkpd5z

Instituto Nacional de Estadística y Censos, INDEC (2020). Informes técnicos, incidencia de la pobreza y la indigencia en 31 aglomerados urbanos. Primer Semestre de 2020. INDEC. https:// www.indec.gob.ar/uploads/informesdeprensa/eph_pobreza_01_200703093514.pdf 
Instituto Nacional de Estadística y Censos, INDEC (2010). Censo Nacional de Población, Hogares y Viviendas 2010 Censo del Bicentenario, INDEC. https://www.indec.gob.ar/ftp/cuadros/ poblacion/censo2010_tomo2.pdf

Janoschka, M. (2002). El nuevo modelo de la ciudad latinoamericana: fragmentación y privatización. Revista EURE, 28(85), 11-20. https://doi.org/10.4067/s0250-71612002008500002

Mendiola, I. (2013). Regímenes de movilidad y domesticación del espacio. Revista Politica y Sociedad, 49(3), 433-452. https:// doi.org/10.5209/rev_poso.2012.v49.n3.38549

Olguín y Busetti (2003). No todo lo que brilla es oro: La pobreza en San Luis. Ponencia preparada para el VI Congreso Nacional de Estudios sobre el Trabajo. Facultad de Ciencias Económicas, Universidad Nacional de Cuyo, Mendoza, Argentina.

Rodriguez Saá, Alberto (1998). Conferencia San Luis, un destino, San Luis. Centro de Estudios Sociales, San Luis, Argentina.

Sassone, S. (1998). Reestructuración territorial y ciudades intermedias en la Argentina. Signos Universitarios, 18(34), 15-70. https:// p3.usal.edu.ar/index.php/signos/article/view/2314

Scribano (2008). Sensaciones, conflicto y cuerpo en Argentina después del 2001. Revista Espacio Abierto Cuaderno Venezolano de Sociología, (2), 205-230. https://www.redalyc.org/ pdf/122/12217201.pdf

Segovia, M. (2012). El desarrollo urbanístico y espacial de San Luis/ Cuyo-Argentina en la segunda mitad del siglo XX: hacia un modelo de diferenciación socioespacial y funcional de una ciudad mediana [Tesis doctoral]. http://hdl.handle. net/2445/41983

Sennett, R. (1997). Carne y Piedra, el cuerpo y la ciudad en la civilización occidental. Alianza Editorial.

Seveso, E. (2015). Sensibilidad y pobreza. Acerca de las clase(s) media(s), las políticas de asistencia y seguridad. Editorial Puño y Letra.

Seveso, E. (2018). Ciudad, seguridad y territorio: tendencias de estructuración en San Luis (2004-2017). Revista Trabajo y Sociedad, (31), 103-126. https://www.redalyc.org/articulo. oa?id=387359235007

Seveso, E. y Lisdero, P. (2013). Sociologizando: Estrategias de "policiación de la sociedad” y prácticas de securitización ciudada- 
na: una mirada a los mecanismos represivos en contextos neocoloniales. Revista Boletín Científico Sapiens Research, (1), 19-24. https://www.srg.com.co/bcsr/index.php/bcsr/ article/view/88/80

Subsecretaría de Política Económica. (2018). San Luis, Informes Productivos Provinciales. Ministerio de Hacienda de la Nación. https://www.argentina.gob.ar/sites/default/files/informe_ productivo_san_luis.pdf

Schiavo, E. y Gelfuso, A. (2018). Urbanismo de mercado. Las ciudades latinoamericanas y el neoliberalismo realmente existente. Revista Cadernos Metropole, 20(42), 424-442.

Sheller, M. y Urry, J. (2018). Movilizando el nuevo paradigma de las movilidades. Revista Quid 16, (10), 333-355. https://publicaciones. sociales.uba.ar/index.php/quid16/article/view/3202/pdf_36

Svampa, M. (2005). La Sociedad Excluyente, la Argentina bajo el signo del neoliberalismo. Editorial Taurus.

Szupiany, E. (26 de octubre de 2016). Corredores viales, indefinición territorial, y fragmentación socio-espacial. Los ejes de la expansión norte de la ciudad de Santa Fe. IX Conferencia del International Forum of Urbanism, Del conocimiento al desarrollo, nuevos desafíos de la universidad en la gestión del desarrollo urbano contemporáneo. Facultad de Arquitectura, Diseño y Urbanismo, Universidad de La República, Montevideo, Uruguay.

Trivi, N. (25 a 27 de septiembre de 2014). La política turística de la provincia de San Luis durante el neodesarrollismo. Visión e intervención del territorio para un proyecto político. Ponencia preparada para el V Congreso Latinoamericano de Investigación turística. Facultad de Ciencias Humanas y Ciencias de la Educación, Neuquén, Argentina.

Valles, M. (1999). Técnicas cualitativas de investigación social, reflexión metodológica y práctica profesional. Síntesis Sociológica.

\section{Noticias y notas de periódicos}

Agencia de Noticias de San Luis (2012, 17 de diciembre). Integración y progreso regional: El Gobierno inauguró la nueva estación de ómnibus. ANSL. Obtenido de http://agenciasanluis.com/ notas/2012/12/17/integracion-y-progreso-regional-el-gobierno-inauguro-la-nueva-terminal-de-omnibus/ 
Agencia de Noticias San Luis (2019, 9 de diciembre). Mensaje completo del gobernador Alberto Rodriguez Saa. Agencia de Noticias San Luis. Obtenido de http://agenciasanluis.com/ notas/2019/12/09/mensaje-completo-del-gobernador-alberto-rodriguez-saa/

Catalfamo, E. (2014, 24 de febrero). Los drones sobrevolaron la gira institucional. Agencia de Noticias San Luis. Obtenido de http:// agenciasanluis.com/notas/2014/02/24/los-drones-sobrevolaron-la-gira-institucional/

Diario de La República (2017, 27 de septiembre). Instalarán trescientas nuevas antenas de wifi 3.0 en el interior. Diario de La República. Obtenido de https://www.eldiariodelarepublica.com/ nota/2017-9-27-7-57-13-instalaran-trescientas-nuevas-antenas-de-wifi-3-0-en-el-interior

Diario de La República (2019, 29 de agosto). San Luis, otra vez reconocida por sus políticas digitales. Diario de La República. Obtenido de https://www.eldiariodelarepublica.com/ nota/2019-8-29-8-17-0-san-luis-otra-vez-reconocida-porsus-politicas-digitales

El Chorrillero (2019, 4 de diciembre). Docentes no pueden cobrar por el hackeo al Data Center. El Chorrillero. Obtenido de https:// elchorrillero.com/nota/2019/12/04/179657-docentes-nopueden-cobrar-por-el-hackeo-al-data-center/amp/

Ministerio de Obras Públicas e Infraestructura (2016, 10 de noviembre). Parque a orillas del Río San Luis. Agencia de Noticas San Luis. Obtenido de http://agenciasanluis.com/notas/2016/11/10/ parque-a-orillas-del-rio-san-luis/

Torres, A. (2019, 2 de julio). Los trabajos de "Pinta San Luis" continúan embelleciendo al barrio José Hernández. Agencia de Noticias San Luis. Obtenido de http://agenciasanluis.com/notas/2019/07/02/los-trabajos-de-pinta-san-luis-continuanembelleciendo-al-barrio-jose-hernandez/ 